J Mol Biol. 2015 July 17; 427(14): 2360-2378. doi:10.1016/j.jmb.2015.05.007.

\title{
A Direct Interaction With RNA Dramatically Enhances the Catalytic Activity of the HIV-1 Protease In Vitro
}

\author{
Marc Potempa $^{a}$, Ellen Nalivaika ${ }^{d}$, Debra Ragland ${ }^{d}$, Sook-Kyung Lee ${ }^{b, c}$, Celia A. Schiffer ${ }^{d}$, \\ and Ronald Swanstrom ${ }^{\mathrm{a}, \mathrm{b}, \mathrm{c},{ }^{*}}$ \\ aDepartment of Microbiology and Immunology, University of North Carolina at Chapel Hill, Chapel \\ Hill, NC 27599, USA \\ bDepartment of Biochemistry and Biophysics, University of North Carolina at Chapel Hill, Chapel \\ Hill, NC 27599, USA \\ CUNC Center for AIDS Research, University of North Carolina at Chapel Hill, Chapel Hill, NC \\ 27599, USA \\ ${ }^{d}$ Department of Biochemistry and Molecular Pharmacology, University of Massachusetts Medical \\ School, Worcester, MA 01605, USA
}

\section{Abstract}

Though the steps of human immunodeficiency virus (HIV)-1 virion maturation are well documented, the mechanisms regulating the proteolysis of the Gag and Gag-Pro-Pol polyproteins by the HIV-1 protease (PR) remain obscure. One proposed mechanism argues that the maturation intermediate p15NC must interact with RNA for efficient cleavage by the PR. We investigated this phenomenon and found processing of multiple substrates by the HIV-1 PR was enhanced in the presence of RNA. The acceleration of proteolysis occurred independently from the substrate's ability to interact with nucleic acid, indicating that a direct interaction between substrate and RNA is not necessary for enhancement. Gel-shift assays demonstrated the HIV-1 PR is capable of interacting with nucleic acids, suggesting RNA accelerates processing reactions by interacting with the PR rather than the substrate. All HIV-1 PRs examined have this ability; however, the HIV-2 PR does not interact with RNA, and does not exhibit enhanced catalytic activity in the presence of RNA. No specific sequence or structure was required in the RNA for a productive interaction with the HIV-1 PR, which appears to be principally, though not exclusively, driven by electrostatic forces. For a peptide substrate, RNA increased the kinetic efficiency of the HIV-1 PR by an order of magnitude, affecting both the turnover rate $\left(\mathrm{k}_{\mathrm{cat}}\right)$ and substrate affinity $\left(K_{m}\right)$. These results suggest an allosteric binding site exists on the HIV-1 PR, and that HIV-1 PR activity during maturation could be regulated in part by the juxtaposition of the enzyme with virionpackaged RNA.

(C) 2015 Published by Elsevier Ltd.

*Corresponding author. CB7295 Lineberger Cancer Center, Room 22-006, University of North Carolina at Chapel Hill, Chapel Hill, NC, 27599. Tel.: 919-966-5710; Fax: 919-966-8212; risunc@med.unc.edu.

Publisher's Disclaimer: This is a PDF file of an unedited manuscript that has been accepted for publication. As a service to our customers we are providing this early version of the manuscript. The manuscript will undergo copyediting, typesetting, and review of the resulting proof before it is published in its final citable form. Please note that during the production process errors may be discovered which could affect the content, and all legal disclaimers that apply to the journal pertain. 


\section{Graphical abstract}

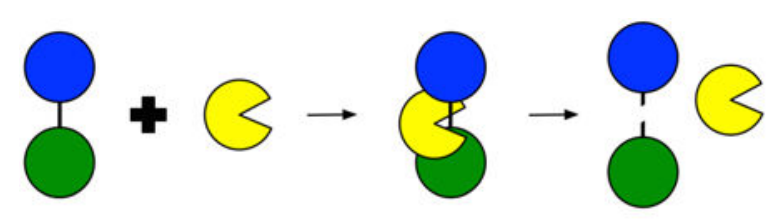

MA-CA HIV-1 Protease

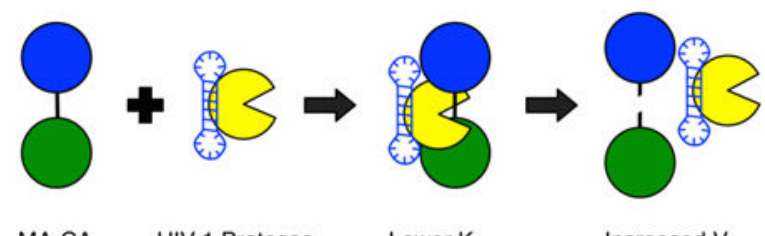

$\begin{array}{llll}\text { MA-CA } & \text { HIV-1 Protease } \\ \text { Interacting with RNA }\end{array} \quad$ Lower $\mathrm{K}_{m} \quad$ Increased $\mathrm{V}_{\max }$

\section{Keywords}

Gag; Maturation; p15NC; Protease; Allosteric Binding Site

\section{Introduction}

For the human immunodeficiency virus (HIV)-1 to spread from cell-to-cell the virus must assemble a particle capable of leaving its host cell without re-infecting the same cell. HIV-1 accomplishes this by constructing the virion as a rigid [1], non-infectious entity [2], and then later converting the particle into a mature, infectious form [3]. The timing of this transfiguration is critical for viral infectivity since prematurely initiating $[4,5]$ or slowing the kinetics of maturation by reducing the number of active HIV-1 protease (PR) molecules [6-8] both disrupt the production of infectious viruses. This, therefore, requires the virus to employ regulatory mechanisms that manage the assembly, release, and maturation steps of the virus lifecycle. Many of these mechanisms concern the activity of the HIV-1 PR.

During assembly HIV-1 particles consist of two structural polyproteins, Gag and GagProPol. Both share the same first four domains - matrix (MA), capsid (CA), spacer peptide 1 (SP1), and nucleocapsid (NC) - but differ in having either a second spacer peptide (SP2) and a domain called p6 (in Gag) or a transframe domain and monomers of the viral enzymes PR, reverse transcriptase, and integrase (in Gag-Pro-Pol). The mass assembly of these proteins on the plasma membrane triggers the budding process, which is completed with the help of the host endosomal sorting complex required for transport (ESCRT) machinery [9]. It is then, concurrent to or immediately after budding, that the HIV-1 PR activates to begin the maturation step of the lifecycle [3].

The HIV-1 PR is a dimer of two identical subunits [10-12], necessitating an interaction between a pair of Gag-Pro-Pol molecules to create the active site of the enzyme. The low stability of this interaction $[13,14]$ and accompanying poor catalytic activity $[14,15]$ restrict PR activation to budding or budded virions, where a high local concentration of Gag-ProPol provides conditions that favor dimerization. The embedded PR overcomes its limited 
functionality through a series of intramolecular cleavage events that free the $\mathrm{N}$ termini of the monomers [14, 16-19], thereby producing a much more stable enzyme capable of completing intermolecular cleavage events [17, 20, 21]. The mature enzyme then proceeds to cleave the remaining structural polyproteins in a step-wise process that must go to near completion [22-24]. Even modest under-processing at most sites can result in a noninfectious virus particle [6-8, 25-27].

Additional regulatory mechanisms exist to control the order and rate of Gag and GagPro-Pol processing. Principally, the cleavage rate is regulated at the level of the processing site amino acid sequence. Each site has a unique sequence, with no obvious pattern connecting them [28]. Instead, all the sites can occupy a conformation that fits into the conserved shape, i.e. substrate envelope, recognized by the HIV-1 PR [29, 30]. The ability of each site to fill that space therefore defines a key determinant of processing order and rate. For instance, the two processing sites that are cleaved last, $\mathrm{CA} / \mathrm{SP} 1$ and NC/SP2, are the most dynamic sites, suggesting they frequently shift in and out of conformations that do not mimic the substrate envelope [29]. This structural plasticity makes them more difficult to cleave. Secondarily, the rate of cleavage for the $\mathrm{CA} / \mathrm{SP} 1, \mathrm{SP} 2 / \mathrm{p} 6$, and SP1/NC processing sites also may exhibit some dependence on contextual determinants [31-33].

A role for RNA as a cofactor has also been suggested. Maturation generates an intermediate called p15NC, which is comprised of the NC, SP2, and p6 domains of Gag. The next step of processing requires cleavage at the SP2/p6 site, but this does not readily occur in the absence of RNA when examined in vitro [34-36]. In the presence of RNA, (or select DNA oligonucleotides), the rate of processing by the HIV-1 PR dramatically increases. In contrast, the cleavage rate of a truncated MA/CA substrate remained unaffected after the removal of RNA from the reaction system [35]. Since p15NC contains the principal viral RNA-binding protein, a mechanism was proposed in which an interaction between RNA and p15NC induces a conformational change in the protein that exposes a buried cleavage site, and/or stabilizes the conformation of the SP2/p6 site to make it a more suitable substrate [35]. In agreement with this hypothesis, the SP2/p6 site is one of the more dynamic cleavage sites, behind only CA/SP1 and NC/SP2 [29]. Given the close proximity of the SP1/NC site to the RNA-binding domains, such a mechanism might also affect SP1/NC processing. Consistent with this, a 30-mer single-stranded DNA molecule was recently shown to increase the rate of SP1/NC processing within a truncated Gag polyprotein [31].

In an effort to study RNA-dependent processing, we established a two-substrate proteolysis system in which cleavage of the $\mathrm{p} 15 \mathrm{NC}$ protein by the PR could be measured in tandem to the rate of cleavage of an internal control protein that was purportedly unaffected by nucleic acid. Contrary to prior results, we found both substrates exhibited an increased processing rate in the presence of RNA. Additional single-substrate assays with globular and peptide substrates demonstrated that RNA enhances processing in a substrate-independent manner. This led us to hypothesize that the critical interaction occurs between RNA and the HIV-1 PR, an interaction substantiated with a gel-shift assay. Examination of a panel of HIV-1 PRs demonstrated that this enzyme-RNA interaction is conserved across multiple subtypes, as well as in patient-derived drug-resistant enzymes. In contrast, the HIV-2 PR does not interact with RNA, and does not cleave its substrates more efficiently with RNA present. 
The interaction between the HIV-1 PR and RNA is primarily electrostatic in nature, although sequence and structural determinants within the polyanion may also play a role. Use of a tethered dimer of the HIV-1 PR revealed RNA-enhanced cleavage does not result from increased dimer stability. While the exact mechanism of enhancement has not yet been identified, we did determine that RNA affects both the $K_{m}$ and $\mathrm{k}_{\text {cat }}$. These findings support the existence of an allosteric binding site on the HIV-1 PR, and raise the possibility that PR activity during assembly could be regulated in part by the juxtaposition of the PR and virionpackaged RNA.

\section{Results}

\section{Multiple substrates of the HIV-1 PR exhibit an enhanced rate of proteolysis in the presence of RNA}

We first documented a two-substrate protease assay where the rate of $\mathrm{p} 15 \mathrm{NC}$ processing could be measured relative to an internal control protein. To demonstrate that we could independently measure multiple substrates in a single reaction, we performed a time-course experiment with two substrates containing the canonical MA/CA cleavage site. One substrate consisted of the entirety of the MA and CA domains (MA/CA); the other substrate had a GST-tag fused to the $\mathrm{N}$ terminus of MA and a CA region truncated at amino acid 145 [32] (GMC $\Delta$ ). This truncation occurred between the $\mathrm{N}$ - and $\mathrm{C}$-terminal domains of $\mathrm{CA}$, which exist as two separate domains [37, 38], ostensibly leaving the conformation of the MA/CA cleavage site unaffected. In addition, these $\mathrm{N}$ - and $\mathrm{C}$-terminal changes allowed the two forms of MA/CA to migrate to different positions in a polyacrylamide gel in both the uncleaved and the cleaved states (Figure 1a). As we have observed previously [26], both substrates were processed in parallel and at nearly identical rates (Figure 1a and 1b). Thus, the two-substrate system enables the direct comparison of relative rates of cleavage by the HIV-1 protease using pairs of protein substrates. For this analysis we have relied on coomassie staining of the proteins and the disappearance of substrate over time to provide flexibility in the types of proteins that can be analyzed.

We sought to determine whether we could observe RNA-dependent rate enhancement of p15NC cleavage by substituting p15NC into the reaction system for the GMC $\Delta$ protein. Due to the poor staining profile of p15NC, its final concentration in the reaction was four-fold higher than that of the MA/CA substrate. In the absence of RNA (Figure 1c, left panel), cleavage of both MA/CA and p15NC was observed. Additional reactions performed with or without nuclease pre-treatment were indistinguishable (data not shown), affirming that these reactions were devoid of RNA. The percent substrate remaining was quantified by densitometry and plotted as a function of time (Figure 1d, dashed lines). Product formation for MA/CA was easily observable, however we could not unequivocally identify the products of p15NC cleavage. One stained poorly, and the other product ran to the same location on the gel as a contaminant remaining after protein purification. To confirm the $25 \%$ drop in p15NC band intensity we observed was in fact processing of the p15NC substrate by the HIV-1 PR, we performed the reaction in the absence of PR and found that there was no observable change in either substrate (data not shown), suggesting the decrease 
in $\mathrm{p} 15 \mathrm{NC}$ band intensity was due to PR cleavage. Thus, in this system, the MA/CA protein was processed approximately 2.5 -fold faster than $\mathrm{p} 15 \mathrm{NC}$ in the absence of RNA.

When we performed the two-substrate reaction in the presence of long, heteropolymeric RNA, a 532-base transcript derived from the p15NC region of the HIV-1 genome, we found the rate of substrate disappearance accelerated for both substrates (Figure 1c and 1d). This result contradicts previously published work that found MA/CA cleavage unaffected by the presence of nucleic acid [31,35]. Nonetheless, we consistently observed a 15 -fold increase in the rate of p15NC cleavage in concert with an 8-fold increase in the rate of MA/CA processing. Our results argue that substrates that do not contain NC can also exhibit an enhanced rate of cleavage in the presence of RNA.

\section{RNA-dependent rate enhancement is a substrate-independent phenomenon}

In order to confirm that RNA-dependent enhancement of MA/CA cleavage occurs independently of p15NC, we performed single-substrate proteolysis assays in the presence and absence of RNA. In our single-substrate assays, the MA/CA protein was labeled with the Lumio Green Reagent after mutagenesis of the Cyclophilin A loop in CA to create a fluor binding site [26]. This label binds with high specificity and in a one-to-one molar ratio with the substrate, allowing specific and more sensitive detection of the substrate and the CA product compared to the coomassie stain (Figure 2a). As a result, we could reliably determine the percent product formed (Intensity of CA band $\times 100 \% \div$ total fluorescence intensity of all bands in the lane), greatly increasing the accuracy of our data collection. Unfortunately, the label could not be used with the p15NC substrate because the zinc-finger domains in p15NC also bind to the Lumio Green Reagent. With this assay, we could accurately determine changes in the MA/CA cleavage rate of up to 40-fold. However, when comparing the no-RNA to plus-RNA reactions, we detected a fold enhancement beyond that value. Therefore, we only estimate the rate of MA/CA cleavage as 80- to 90-fold faster in the presence of RNA (Figure 2b). The magnitude by which MA/CA cleavage was accelerated in single substrate assays was considerably greater than in the two-substrate assay. Several explanations likely account for this discrepancy: the increased sensitivity of the fluorescence-based assay allowed more precise determination of reaction progress while under near steady-state conditions; the potential presence of multiple RNA-binding proteins in the two-substrate assay meant there was competition for RNA, which limited the effect; and, owing to an inability to purify p15NC to high concentrations, the ionic strength of the two-substrate assay was likely higher than anticipated due to a substantially larger contribution of protein storage buffer to the reaction mixture. Notably, raising the ionic strength of the reaction by increasing the salt concentration drastically reduces the magnitude of the RNA-enhancement effect [39], even in single-substrate MA/CA assays (see below).

Since MA/CA also exhibited RNA-dependent enhancement, we considered the possibility that this effect resulted from an interaction between MA/CA and RNA. MA contains a highly basic region on the globular head of the protein capable of binding nucleic acid [40-44]. Because the RNA species used in prior experiments was a 532-base transcript derived from the p15NC region of the HIV-1 genome, it was poorly suited for use in a gel- 
shift assay. To identify a surrogate nucleic acid, we tested the ability of two short ssDNA oligonucleotides, N5 (21 bases) and ODN17 (17 bases), to accelerate MA/CA processing. Both molecules had previously been reported to enhance p15NC processing similarly to RNA, although not as potently $[34,36]$. In agreement with previous reports, both N5 and ODN17 increased the rate of processing, but to a much lower degree than RNA (Supplementary Figure 1).

Using ODN17, we performed a gel-shift assay to determine the ability of MA/CA to bind to nucleic acid. Under native conditions, ODN17 runs as two species (Figure 2c, left panel); presumably, the lower species corresponds to single-stranded molecules, while the upper band may represent a G-quadruplex structure that ODN17 has the potential to form [34, 45]. In concert with the addition of increasing amounts of MA/CA to the binding reactions, (from $0 \mu \mathrm{M}$ in lane 1 to $12 \mu \mathrm{M}$ in lane 9), both the upper and lower bands progressively diminished (Figure 2c, right panel), and a new band appeared toward the top of the gel. The new band overlaps with where the MA/CA protein runs (Figure 2c, center panel), signifying that the $\mathrm{MA} / \mathrm{CA}$ protein interacts with nucleic acid.

Addressing the question of whether this interaction was required for the enhanced rate of MA/CA processing, we replaced the lysines in the $\mathrm{K}_{26} \mathrm{KQYK}_{30}$ sequence of MA with alanines to generate the mutant protein MA/CA-AAA. In a previous report, mutating these lysines disrupted the residual RNA-binding ability of Gag molecules whose NC domain had been deleted [43]. Consistent with those results, MA/CA-AAA was severely attenuated in its ability to interact with ODN17 (Figure 2d). If an interaction between MA/CA and nucleic acid was responsible for its increased cleavage rate, then we should have found enhanced processing of MA/CA-AAA to be considerably reduced or nonexistent. However, RNAdependent enhancement of MA/CA-AAA processing still occurred, and at a nearly identical magnitude (Figure $2 b$, gray lines). These results suggest that RNA-dependent enhancement is independent of the substrate.

In order to confirm the lack of requirement for an interaction between substrate and RNA, we performed proteolysis assays utilizing a 12-amino acid peptide as the substrate. The HIV Protease Substrate 1 (Sigma) is a fluorogenic substrate too small to interact with RNA and simultaneously be cleaved by the HIV-1 PR; conveniently, this peptide also contains the same cleavage site sequence as the MA/CA protein. Adding RNA to the peptide proteolysis reaction still accelerated the rate of the reaction, though only by 20 -fold (Figure 3 ).

Differences in reaction conditions for the peptide (i.e. $\mathrm{pH}$ ), and/or the absence of contextual determinants could account for the reduced magnitude of the effect relative to the globular MA/CA substrate. Nonetheless, the results of the peptide assay show that the increased reaction rate observed upon addition of RNA is independent of the substrate.

\section{The HIV-1 PR can directly interact with nucleic acid}

Since an interaction between RNA and substrate is not the mechanism driving RNAdependent enhancement, we hypothesized that an interaction was occurring between RNA and the HIV-1 PR. We again used ODN17 as a surrogate for RNA-binding, and performed gel-shift assays utilizing the HIV-1 PR as the protein in each binding reaction. Similar to the wild-type MA/CA protein, adding progressively more PR resulted in the disappearance of 
the upper oligonucleotide band (Figure 4, left panel). In this case the fluorescence intensity of the lower band remained relatively unchanged regardless of the amount of PR present in the binding reaction. Under native conditions, the HIV-1 PR does not enter the gel, likely because of its basic profile (HIV-1 PR has an isoelectric point of 9.1), so there is no overt overlapping band in both stains. Nonetheless, we infer the presence of a PR-ODN17 complex from the selective loss of the upper oligonucleotide band and a low level of fluorescence in the wells of the central lanes of both SYBR gold and SYPRO ruby stains. The fluorescence may disappear from the latter wells because the addition of more HIV-1 PR increases the net charge of the PR-ODN17 complexes so that the complexes flow into the running buffer rather than remain in the well. From this, we conclude that the HIV-1 PR can directly interact with nucleic acids.

\section{RNA accelerates processing by HIV-1 PRs from multiple subtypes and from drug resistant variants, but not processing by HIV-2 PR}

Given that we had only shown a single variant of a subtype B HIV-1 PR was capable of interacting with RNA to enhance its activity, we expanded our data set to include HIV-1 PRs of subtype C and CRF01_AE, as well as an HIV-2 PR (Supplementary Table 1). We also tested several patient-derived, drug-resistant subtype B PRs to determine whether the effect is maintained after significant changes to the amino acid sequence (19-26 substitutions from the PR of the SF2 isolate of HIV-1 subtype B used in the prior experiments). All three wild-type HIV-1 PRs exhibited a 100-fold or greater increase in the rate they processed the MA/CA protein in the presence of RNA relative to their respective no-RNA controls (Figure 5). The drug-resistant HIV-1 subtype B PRs likewise demonstrated enhanced catalytic activity in the presence of RNA, although there was considerably more variability in the magnitude of the effect for these enzymes. Despite the variability in magnitude, VSL23, the PR whose activity was least accelerated, still cleaved MA/CA 30-fold more quickly. The only enzyme entirely unaffected by the presence of RNA was the HIV-2 PR. For this latter assay the cleavage site of MA/CA was adapted to reflect the canonical site for HIV-2, allowing the substrate to be efficiently cleaved by the enzyme (data not shown). Consistent with these results, we found that the HIV-2 PR did not interact with nucleic acid in a gel-shift assay (Supplementary Figure 2; note the HIV-2 PR with its lower isoelectric point of 5.3 enters the gel). Both the PR-dependent variability in the magnitude of the effect, and the lack of enhancement for the HIV-2 PR further demonstrated that RNA-dependent enhancement results from an interaction between RNA and the HIV-1 PR rather than with the substrate.

\section{Long, heteropolymeric RNA is the most effective enhancer of HIV-1 PR activity, but small ssDNA molecules and tRNA are still functional enhancers}

Whereas MA/CA interacted with both the upper and lower ODN17 bands in the gel-shift assay, the HIV-1 PR demonstrated a selective interaction with only the upper ODN17 species. Additionally, ODN17 and N5 were considerably less potent enhancers than p15 RNA, requiring much higher concentrations to be effective in our earlier assays. These data raised the possibility that a specific interaction might occur between enzyme and nucleic acid, which was fulfilled much more capably by some component of the p15 RNA transcript used in our assays. To determine whether p15 RNA contains some specific feature required 
for an interaction between the HIV-1 PR and nucleic acid, we generated dose-response curves for multiple different RNA transcripts, yeast tRNA, and the N5 and ODN17 singlestranded DNA molecules. All long (>400 bases), heteropolymeric RNAs accelerated the reaction equivalently (Figure 6a), including transcripts that were not derived from the HIV-1 genome (data not shown). The long RNAs also had very similar EC50 values (Table 1) that were even closer to identical when adjusted for length (EC50/nt). Even though N5 and ODN17 were roughly one-tenth as effective as long heteropolymeric RNA in the magnitude of the enhancement effect, both still accelerated MA/CA processing by about 10-fold. Though the EC50s of N5 and ODN17 were in the $\mu \mathrm{M}$ range, the EC50/nt were reasonably similar to those of long heteropolymeric RNA. Yeast tRNA grouped with the singlestranded DNA molecules regarding the magnitude of enhancement, but the EC50 value was nearer the RNA transcripts. Thus tRNA had the lowest EC50/nt, but this value was still only two-fold lower than most other nucleic acids. We conclude that long, heteropolymeric RNAs are the most potent enhancers of HIV-1 PR activity, but because all six nucleic acids tested had very similar EC50/nt the amount of nucleic acid, rather than a specific sequence or structure, appears to be the critical determinant. However, this does not yet address why long heteropolymeric RNA was 10-fold more potent in the magnitude of enhancing HIV-1 PR activity than the other nucleic acids (i.e. 100-fold vs 10-fold enhancement), nor does it explain the selective binding of the oligonucleotides observed in the gel-shift assay.

As a means of further investigating the apparent selectivity of the HIV-1 PR for the larger ODN17 species, as well as the discrepancy in the magnitude of the effect between long RNA transcripts and single-stranded DNA molecules, we increased our catalogue of oligonucleotides and tested each for their ability to enhance PR activity. Figure $6 \mathrm{~b}$ and $6 \mathrm{c}$ contain the results from a selection of these molecules, all of which are between 17 and 21 nucleotides in length (Supplementary Table 2). Of the twelve molecules shown, six of them (ODN17, N5, N5cgmut, N10, G6A6C6, G6A12) enhanced the rate of the reaction by at least 5-fold (Figure 6c); the other six were ineffective even at concentrations exceeding $10 \mu \mathrm{M}$. Among the single-stranded DNA molecules capable of enhancing the reaction, all but the Crich N10 molecule formed slower migrating species when electrophoresed through a 6\% polyacrylamide gel (Figure 6b). However, we cannot definitively state whether N10 did or did not form a secondary species because the SYBR gold stain is much less effective at staining C-rich oligonucleotides (e.g. Figure 6b, C6A12), and C-rich nucleic acids are capable of forming higher order multimeric species [46]. With the possible exception of $\mathrm{N} 10$, these results are in accordance with the gel-shift assay where only the larger nucleic acid species interacted with the HIV-1 PR.

We also noticed a direct correlation between the migration distance in the gel, where observable, and the magnitude of the enhancer effect (Figure $6 \mathrm{~b}$ and $6 \mathrm{c}$ ). Preheating aliquots of the oligonucleotides before use confirmed the importance of these multimeric and/or structured species - only those whose slower migrating species remained after heating retained their enhancer activity (Supplementary Figure 3) - and also strengthened the correlation between migration pattern and effect magnitude. G6A6C6 lost one of its two larger species after heating, with the remaining band migrating to a position similar to the species present in the unheated N5 aliquots. The magnitude by which the heated G6A6C6 preparation enhanced HIV-1 PR activity resembled that of unheated N5, highlighting the 
proposed relationship. These data suggest that the interaction between the HIV-1 PR and nucleic acid is primarily electrostatic in nature, requiring a polyanion of some particular size or conformation rather than a specific sequence. Also, the potency of an enhancer's effect may be determined by the size and/or conformation of the molecule.

\section{The interaction between the HIV-1 PR and nucleic acid is principally electrostatic, but additional factors affect the magnitude of enhancement}

If the HIV-1 PR-RNA interaction is primarily electrostatic in nature, then a non-nucleic acid polyanion should be sufficient to enhance the enzyme's catalytic activity. To test this, we utilized heparin as the polyanion in single-substrate proteolysis assays and generated a doseresponse curve (Figure 7a). As expected, heparin enhanced proteolysis, accelerating the rate of the reaction by up to 30 -fold. This value put heparin squarely between long, heteropolymeric RNA and the short single-stranded DNA molecules in effectiveness. With the expected size of commercially produced heparin molecules to be $17-19 \mathrm{kDa}$, an equivalently sized molecule of RNA would be approximately 53-60 nucleotides. As this size fits between the HIV-1 RNA transcripts and the single-stranded DNA molecules, the magnitude of the effect remains consistent with the proposed relationship between size and effectiveness of the polyanion. We also tested a polycation spermine (Sigma) in our system, but it had no effect on HIV-1 or HIV-2 PR activity at all concentrations examined (data not shown). However, we cannot rule out the possibility that its ineffectiveness was the result of the small size of individual spermine molecules.

If an electrostatic interaction were sufficient, we hypothesized that homopolymers of each deoxynucleotide should be equally effective at accelerating the rate of proteolysis. We generated dose response curves for 49-mers of poly (dA), poly(dC), and poly(dT), (Figure $7 b)$. Owing to synthesis constraints, the poly(dG) molecule contained an adenosine every seventh base (Supplementary Table 1). We found that only three of the four nucleic acid homopolymers accelerated the rate of MA/CA cleavage, with poly $(\mathrm{dA})$ incapable of enhancing the rate of the reaction by any significant amount under the conditions tested. The three other oligonucleotides yielded similar results in both the magnitude of their effect and their EC50 values (Table 1). Furthermore, the 15-20-fold rate enhancement observed was also consistent with the predicted result based upon the size of the molecules. The observation that poly $(\mathrm{dA})$ was ineffective indicates that while a polyanion is necessary, it is not sufficient for enhancing proteolysis.

Additionally, if the PR-RNA interaction is electrostatic in nature, the $\mathrm{pH}$ and ionic strength of the reaction mixture should have considerable influence over the enhancer effect. The intracellular ionic strength of mammalian cells is approximately $0.15 \mathrm{M}$, which is similar to the conditions of our single-substrate assays. Increasing the ionic strength to $0.2 \mathrm{M}$ by adding $\mathrm{NaCl}$ to the reaction buffer reduced the magnitude of the effect to only a 10-fold enhancement. In reactions with an ionic strength of $0.5 \mathrm{M}$ or higher, RNA had no effect on the rate of proteolysis (Supplementary Figure 4A). Though the $\mathrm{pH}$ at the site of virus assembly, budding, and maturation has not yet been formally determined, the cytosolic $\mathrm{pH}$ of lymphocytes is known to be approximately 7.2 [47]. When we performed assays at $\mathrm{pH}$ 7.2, select shorter nucleic acids, including tRNA and G6A6C6, still accelerated MA/CA 
processing albeit to a very limited degree; the remaining 17-21 single-stranded DNA molecules became ineffective (data not shown). Long heteropolymeric RNA was also still effective, but similarly to raising the ionic strength, the magnitude of the effect decreased to approximately eightfold enhancement (Supplementary Figure 4b).

\section{RNA-dependent enhancement is not the result of a change in HIV-1 PR monomer-dimer equilibrium}

We attempted to discern the mechanism by which RNA and other polyanions enhance HIV-1 PR catalytic activity. As the HIV-1 PR is a non-tethered dimer, its monomeric and dimeric forms exist in a state of equilibrium [48]. We hypothesized that RNA may shift the equilibrium by stabilizing or promoting the dimeric form of the PR, effectively increasing the number of active PR molecules in the reaction. Accordingly, tethering the dimer together should abrogate the RNA-enhancement phenotype. We generated an HIV-1 PR dimer where the $\mathrm{C}$ terminus of one monomer is tethered to the $\mathrm{N}$ terminus of the second monomer by a flexible five amino acid linker. After controlling for the number of active sites present in the proteolysis reactions, we generated a dose-response curve for the tethered dimer with p15 RNA as the enhancer (Figure 8). Compared to the control, no differences were observed between the tethered dimer and wild type PRs. RNA accelerated the rate of both reactions by more than 80 -fold, and with similar EC50 values ( $36 \mathrm{nM}$ for wild type, $35 \mathrm{nM}$ for the tethered dimer). Therefore, RNA-dependent enhancement does not result from promoting dimeric interactions between HIV-1 PR monomers.

\section{The HIV-1 PR-RNA interaction lowers the $K_{m}$ and increases the $V_{\max }$ of the proteolysis reaction}

In order to determine the effect of RNA on the enzymatic parameters of the PR, we used the fluorogenic peptide substrate to generate Michaelis-Menten plots and determined the effect of RNA on $K_{m}$ and $\mathrm{V}_{\max }$. In the presence of RNA, $K_{m}$ decreased by almost 4-fold, while $\mathrm{V}_{\max }$ increased by 3 -fold (Figure 9 and Table 2). The lower $K_{m}$ indicates that RNA increases the affinity of the HIV-1 PR for its substrates, while the higher $\mathrm{V}_{\max }$ demonstrates that RNA also increases the rate of the catalysis step. Using $\mathrm{V}_{\max }$ as a surrogate for $\mathrm{k}_{\text {cat }}$ we calculated the relative specificity constant $\left(\mathrm{k}_{\mathrm{cat}} / K_{m}\right)$ for the enzyme with and without RNA present finding that RNA increases the relative $\mathrm{k}_{\text {cat }} / K_{m}$ for the peptide reaction by an order of magnitude (Table 2). Thus the HIV-1 PR is 10-fold more efficient at cleaving the peptide substrate when interacting with RNA.

There were two other notable features of the plots. First, once the peptide substrate concentration reached $25 \mu \mathrm{M}$, the initial velocity of the reactions containing RNA began to decline, eventually converging with the minus-RNA curve. The peptide concentration where this reduction began changed depending upon the amount of RNA present in the reaction (data not shown), suggesting that the reduction in effect happened because the substrate was outcompeting the PR for binding to the RNA at these high concentrations. These data points were excluded for the determination of $K_{m}$ and $\mathrm{V}_{\max }$ in the presence of RNA. Second, despite the HIV-1 PR having only a single active site, the Hill coefficient was equal to 1.9 for the minus-RNA plot. The hill coefficient for the plus-RNA curve was calculated to be 1.9 as well; however, because of the low $K_{m}$, the rapid loss of steady-state conditions at low 
starting peptide concentrations, and background levels of fluorescence, we did not have enough data points below the $K_{m}$ to show this with confidence. We did attempt to gather more data by lowering the PR concentration, and in those experiments still found a value for the Hill coefficient to be greater than one (data not shown), suggesting the Hill coefficient is greater than one irrespective of whether RNA is present. We cannot explain this result, though sigmoidal Michaelis-Menten curves can be observed in the absence of cooperativity [49].

\section{Discussion}

Converting a nascent HIV-1 particle into a mature infectious virion requires the viral PR to cleave the Gag and Gag-Pro-Pol polyproteins in a precise order [22-24]. Given the complexity of this process, numerous regulatory mechanisms exist to direct the PR towards specific processing sites at various phases of maturation. These determinants of cleavage include processing site amino acid sequence [28-30], the local structural context [20, 31-33], and cofactors such as RNA or DNA [31,34-36]. An effect of RNA or other nucleic acids on processing rate has previously been reported only for cleavage sites nearby $\mathrm{NC}$ [31, 34-36], yet we found RNA accelerated the cleavage of substrates completely independent from NC. Moreover, accelerated processing of the MA/CA-AAA and peptide substrates indicated a substrate-RNA interaction was not required. We hypothesized that an enzyme-RNA interaction could enhance PR activity, and found the HIV-1 PR capable of interacting with nucleic acid in a gel-shift assay. The HIV-2 PR lacked this ability, and did not cleave its substrate more efficiently in the presence of RNA, providing corollary evidence. Interactions between the HIV-1 PR and RNA are primarily electrostatic in nature rather than sequence specific, though some additional prerequisites for the polyanion may exist. Mechanistically, RNA both increases the affinity of the HIV-1 PR for its substrates, and accelerates reaction turnover.

Proteolysis reactions that included RNA progressed more rapidly than those without RNA for every substrate tested for cleavage by an HIV-1 PR. This finding is in contrast with the original report, which found the rate of only p $15 \mathrm{NC}$ processing changed in the presence of RNA [35]. Experimental differences could have contributed to overlooking RNA as a general enhancer. In the previous work, most of the assays were limited to the single substrate $\mathrm{p} 15 \mathrm{NC}$, and RNA needed to be removed from the reactions rather than added as a supplement. This carries the inherent risk that some RNA may have remained in the RNAfree reactions. Very low concentrations of long heteropolymeric RNA were sufficient to achieve enhancement (Figure 6), so RNA removal would have needed to be exhaustive. Our two-substrate procedure improved upon these limitations by ensuring the reaction conditions were exactly the same for both p15NC and MA/CA substrates, and by precisely controlling the amount of RNA added to the reaction. We also suspect differences in substrates may have impacted the previous results. Though our MA/CA contained the whole of CA, an unusual truncation of $\mathrm{CA}$ within the $\mathrm{N}$-terminal domain (at amino acid 78) was employed previously. This truncation may have contributed by altering the fold of the MA/CA protein in such a way that it affected its ability to serve as a substrate. Thus, our results are consistent with most of the experiments that identified RNA as an effector of p15NC processing. However, our interpretation of these results is very different in that we find the 
enhancing effect to require an interaction between RNA and the PR rather than RNA and the substrate.

A more recent publication found the rate of SP1/NC processing increased in the presence of a single-stranded DNA molecule [31]. The authors attributed this result to an increased accessibility of the SP1/NC processing site after NC bound the target nucleic acid molecule. Importantly, enhanced SP1/NC processing occurred in the absence of accelerated MA/CA or CA/SP1 cleavage. Such a result would argue in favor of RNA selectively enhancing cleavage of the sites nearby NC. There are several significant differences between this study and ours. In order to prevent aggregation of their substrate, the reactions were performed under high salt conditions (300 mM NaCl). We (Supplementary Figure 4a) and others [39] have demonstrated that nucleic acid-dependent enhancement of PR activity is tempered by increasing the ionic strength of the reaction. Also, they used a much higher substrate concentration and a different form of substrate, which could also affect cleavage site accessibility. Finally, though we did not directly examine the possibility of site-to-site variability in effect, we note that a modest difference in the magnitude of RNA-dependent enhancement was observed for $\mathrm{p} 15 \mathrm{NC}$ and MA/CA in the two-substrate assay. While we have shown a robust effect of RNA on HIV-1 PR activity, it is clear that understanding, and untangling, the effect of RNA on PR and on substrate requires further exploration.

The ability of the HIV-1 PR to bind nucleic acid and have this interaction regulate its catalytic efficiency is not without precedent. Three other viral proteases have been identified that use RNA or DNA as a regulator. The human adenovirus proteinase (AVP) exhibits extremely poor functionality on its own, requiring an 11-amino acid peptide and a nonspecific interaction with DNA or other polyanions to achieve its maximal activity [50-52]. Prototype foamy virus (PFV) PR utilizes a specific sequence in the PFV genome to facilitate its dimerization and activation [53]. In addition, the hepatitis $C$ virus nonstructural 3 protein contains a serine protease domain $\left(\mathrm{NS}^{\mathrm{Pro}}\right)$ that can directly bind nucleic acid $[54,55]$. In contrast to the AVP, PFV PR, and HIV-1 PR, this interaction negatively regulates NS3 3 Pro activity [55]. Thus, enzymes from very different virus families have been identified that can use nucleic acid as an interacting partner.

In addition to our own work, an interaction between HIV-1 PR and RNA has been suggested by one other study [39], though this report used extremely low ionic strength and low $\mathrm{pH}$ conditions. These conditions may have promoted artificial interactions, since they found both polyanions and polycations to be capable of accelerating HIV-1 PR activity; in contrast, we found polycations to be ineffective (data not shown). One additional difference in our results concerns poly(rA), which was reported to enhance PR activity, but we also found ineffective as poly(dA). A possible explanation could be that poly(dA) [56] and poly(rA) $[57,58]$ exist in different structural states at acidic versus neutral $\mathrm{pH}$. Regardless, we demonstrate a functional interaction between the HIV-1 PR and heteropolymeric RNA can occur in environments with ionic strength and $\mathrm{pH}$ conditions likely to be encountered in vivo.

Whether a productive interaction between the HIV-1 PR and RNA actually occurs in vivo remains unknown, however. While acknowledging that in vitro experiments cannot recreate 
the complex environment within an actual virus particle, in our assays with p15NC the NCto-PR dimer ratio was 130:1 and the NC-to-nucleotide ratio was 1:8; the latter ratio is noteworthy because the footprint of $\mathrm{NC}$ is one molecule per eight nucleotides [59, 60]. Thus, in the presence of enough NC to entirely coat the available RNA, and in substrate-to-enzyme conditions that exceed the ratio of NC-to-PR dimer in virus particles (between 20:1 and 40:1), RNA-dependent enhancement was observed. These results would support the possibility that the interaction can occur in vivo. On the other hand, the enhancement effect was reduced when the reaction $\mathrm{pH}$ was raised from 6.5 to 7.2 (Supplementary Figure 4B), implying the effect might be much more limited than what we observed in our reactions. Despite this potential reduced significance, an important role for the interaction cannot yet be ruled out because the $\mathrm{pH}$ at the site of virion biogenesis remains undetermined. Of note, the $\mathrm{pH}$ optimum for globular substrates appears to be slightly below neutral [32]. Altogether, the currently available information is insufficient for determining whether the interaction between the HIV-1 PR and RNA has a biological role.

The HIV-2 PR was the sole enzyme examined that failed to process its substrate more efficiently in the presence of RNA, and failed to interact with nucleic acid in the gel-shift assay. The HIV-1 and HIV-2 PRs have very similar structures [61-63], so the lack of interaction is probably not structural. The more likely explanation is that the negative charge of the HIV-2 PR ( $\mathrm{pI}=5.3$ ) prevents electrostatic interactions with RNA. Visualizing the electrostatic potential of the HIV-1 PR and the HIV-2 PR reveals that the HIV-2 PR has fewer positively charged regions on its surface, especially in the flap regions, which would minimize potential interaction sites for polyanions such as RNA (Figure 10). Though the HIV-2 PR was the exception among the enzymes we examined, it is not the only retroviral PR with a low isoelectric point. Comparing the isoelectric points of 31 primate lentiviruses, a majority of the HIV and SIV strains resembled the HIV-1 Group M PRs, but a sizeable minority had neutral or acidic PRs (Supplementary Table 3). Orthoretrovirus PRs in general also demonstrate variability in charge, though our limited comparison does not rule out the potential for conservation within specific genera (Supplementary Table 4). Regardless, the absence of charge conservation among primate lentiviruses implies a functional interaction in vivo is not required in all settings, and adds further weight to the argument against a biological role for the interaction between the HIV-1 PR and RNA. That the HIV-1 and HIV-2 PRs have similar catalytic properties with peptides in the absence of RNA [64-66] also supports this interpretation. Nonetheless, this information is still insufficient for determining whether an interaction between the HIV-1 PR and RNA actually occurs in vivo, as RNA could regulate Gag processing in different ways for different retroviruses.

All long, heteropolymeric RNAs were equally effective as enhancers, suggesting all the RNAs contained a critical sequence and/or structure, or that neither were required. Because no small molecule was equally potent to the long RNAs, yet some could still enhance PR activity, a sequence requirement is unlikely. Most of the short DNA molecules that improved PR function were G-rich, suggesting a G-quadruplex structure could have been necessary. However, the successful enhancement of proteolysis by poly $(\mathrm{dC})$, poly $(\mathrm{dT})$, and heparin makes it unlikely a specific structure is required. Poly $(\mathrm{dC})$ and poly $(\mathrm{dT})$ also accelerated processing to an equivalent extent as poly(dG), implying no nucleotide was 
preferred either. This leaves electrostatic interactions as the primary means of interaction between enzyme and nucleic acid.

Though an electrostatic attraction appears to be the key requirement, additional determinants also exist that modulate the effectiveness of the interaction. Since the magnitude of enhancement plateaued at lower levels despite higher concentrations of smaller polyanions, simply saturating the binding sites on the HIV-1 PR is not sufficient for achieving a maximum magnitude of the effect. Consequently, the size or length of the polyanion must also be important. Poly (dA) and yeast tRNA point to one other additional requirement, as they were exceptions to this conclusion. Both of these nucleic acids are more rigid than other transcripts: tRNA due to base pairing and base modifications [67], and poly(dA) due to strong base-stacking interactions $[68,69]$. This suggests that the polyanion must have flexibility to serve as an efficient cofactor, in addition to being of sufficient length.

RNA enhances the catalytic activity of PFV PR by promoting its dimerization [53], so we considered this possibility for the mechanism of HIV-1 PR enhancement. Since, the concentration of HIV-1 PR was $100 \mathrm{nM}$ in our reactions, which is well above the $\mathrm{K}_{\mathrm{d}}$ of 6.8 $\mathrm{nM}$ determined for similar conditions of $\mathrm{pH}$, ionic strength, and temperature [48], and the estimated half-life of an HIV-1 PR dimer is approximately 30 minutes [48], most of the PR was dimeric throughout the assay regardless of the availability of RNA. Therefore, acceleration by RNA was likely occurring with already intact PR dimers. The tethered dimer, which does not dissociate like the wild-type PR [70], confirms this conclusion because we saw a nearly identical effect of RNA on tethered dimer activity. Additionally, for a particle with a diameter of $120 \mathrm{~nm}$ and 120-240 Gag-Pro-Pol molecules, the concentration of the monomeric PR is $220-440 \mu \mathrm{M}$, well above the dissociation constant of the PR even while embedded in Gag-Pro-Pol ( $\sim 680 \mathrm{nM})[14]$. The monomer-dimer equilibrium should therefore heavily favor the dimeric species in virus particles. Although we have not examined an independent effect on dimerization of the PR, the ability of RNA to enhance PR activity appears unlikely to be the related to dimerization.

RNA increased both the affinity of the HIV-1 PR for a peptide substrate $\left(K_{m}\right)$ and its molecular activity $\left(\mathrm{k}_{\mathrm{cat}}\right)$, collectively increasing the catalytic efficiency of the HIV-1 PR by an order of magnitude for the peptide reaction. Considering RNA affected peptide proteolysis less than cleavage of the globular MA/CA protein, the change in the specificity constant for reactions with the globular substrates would likely be even more substantial. These data do not, however, illuminate the precise mechanistic explanation for RNAdependent enhancement. As there is a direct interaction, and it does not interfere with substrate binding, RNA more likely interacts with a secondary binding site(s) on the PR. The consistent inferiority in effectiveness of short nucleic acids compared to long heteropolymeric RNA regardless of concentration additionally implies that the polyanion must affect the PR in some way beyond simply saturating the binding site(s) on the PR. Putative allosteric sites have been identified within the flap/hinge region of the PR by means of small molecules [71-73] and existing PR inhibitors [63, 74]. As the flaps seem to have key roles in both substrate binding and catalysis [75, 76], it is possible to speculate that RNA interacts with the PR flaps to facilitate the many conformational rearrangements this highly dynamic region must undergo [77-80]. Of note, the flap regions of the HIV-1 PR 
(residues 37-61) contain a trio of basic amino acids (R/K41, K43 [71], and K55 [71, 74]) that are uncharged in the HIV-2 PR (Figure 10), and these same residues were identified as a key part of at least some binding interactions.

In summary, we have found that the HIV-1 PR interacts directly with nucleic acid, and this interaction drives the accelerated rate of processing observed for $\mathrm{p} 15 \mathrm{NC}$ and other substrates. No specific RNA sequence or structure is necessary for it to serve as an enhancer, but larger and more flexible polyanions are more effective. Though the exact mechanism by which RNA improves the catalytic efficiency of the HIV-1 PR remains undetermined, the net effect on the enzyme is both an increase in substrate-binding affinity and an increase in turnover rate. These data suggest an allosteric binding site may exist on the HIV-1 PR, and argue in favor of viral genomic RNA being an additional regulator of HIV-1 PR activity during virion maturation.

\section{Materials and Methods}

\section{Constructs}

The MA/CA and p15NC regions were amplified by PCR from the pBARK plasmid, which contains the entirety of the gag and pro genes from NL4-3. Primers were designed to add a $6 \times \mathrm{His}$ tag to the $\mathrm{N}$ terminus of each protein, a termination codon at the $\mathrm{C}$ terminus, and flanking NdeI sites. Following digestion with NdeI, the PCR products were cloned into pET-30b (Novagen) to create pET-p15 and pET-MA/CAxTC. The pET-MA/CAxTC plasmid underwent an additional round of mutagenesis to introduce a tetracysteine motif (CCPGCC) in the Cyclophilin A binding loop (His87-Ala92) of CA and create pETMA/CA. Two additional plasmids coding for the alternative MA/CA substrates, MA/CAAAA and HIV-2 MA/CA, are derived from pETMA/CA. For pET-MA/CAaaa, the nucleic acid sequence was altered to change MA amino acids $\mathrm{K}_{26} \mathrm{KQYK}_{30}$ to $\mathrm{A}_{26} \mathrm{AQYA}_{30}$. In the pET-MA/CA-HIV2 construct, the coding sequence for the cleavage site was altered from SQNY/PIVQ to the canonical HIV-2 MA/CA sequence of GGNY/PVQQ. The pET-GMC $\Delta$ construct was created as previously described [32]. The PR region was also amplified out of pBARK and cloned into pET-30b, but without the addition of the $6 \times$-His tag and termination codon, creating pET-PR.

\section{Nucleic Acids}

All long heteropolymeric RNAs were generated by in vitro transcription. The pET-MA/CA, pET-p15NC, and pET-PR plasmids were linearized with $\mathrm{Eco} R V$, and purified with the Qiagen PCR purification kit. The MEGAscript T7 high yield transcription kit (Ambion) was utilized to generate RNA from the linearized DNA according to manufacturer's instructions. RNA was purified from the reactions with the Qiagen RNeasy kit and stored short-term in nuclease-free water at $-20^{\circ} \mathrm{C}$. All short single-stranded DNA molecules were ordered from Sigma-Aldrich, and resuspended in nuclease-free water. Nucleic acid concentrations were determined with a NanoDrop spectrophotometer (Thermo Scientific). 


\section{Expression and Purification of Globular HIV-1 PR Substrates}

Escherichia coli BL21 DE3 lysogens (Novagen) were transformed with plasmids coding for the $15 \mathrm{NC}, \mathrm{MA} / \mathrm{CA}, \mathrm{MA} / \mathrm{CA}-\mathrm{AAA}, \mathrm{HIV}-2 \mathrm{MA} / \mathrm{CA}$, or GMC $\Delta$ proteins. Starter cultures were grown overnight in $2 \times \mathrm{YT}$ media, and then used to inoculate MagicMedia (Invitrogen) for protein production. Expression cultures were grown for 8 hours at $37^{\circ} \mathrm{C}$ and $225 \mathrm{rpm}$, before pelleting by centrifugation and freezing overnight at $-80^{\circ} \mathrm{C}$. Pellets were resuspended in lysis buffer (TBS pH 7.5, 1\% Triton X-100, $2 \mathrm{mM} \beta$-mercaptoethanol) and lysed by sonication. Cellular debris was collected by centrifugation, and the resulting supernatant was applied to Ni-NTA Superflow columns (Qiagen) for purification of the His-tagged proteins by affinity chromatography. Purified proteins were concentrated using Vivaspin Concentrators (GE Healthcare), and underwent buffer exchange into storage buffer ( $20 \mathrm{mM}$ sodium acetate, $140 \mathrm{mM}$ sodium chloride, $2 \mathrm{mM} \beta$-mercaptoethanol, $10 \%$ glycerol, $\mathrm{pH}$ 6.5). Sample pH was confirmed using a micro-pH electrode (Thermo Scientific). Purified protein samples were tested for residual nucleic acid with a NanoDrop spectrophotometer (Thermo Scientific), and the levels were found to be negligible.

\section{HIV-1 Proteases}

Purified HIV-1 proteases were produced as described previously [32, 81]. Oligonucleotides for the heavily mutated variants were designed and purchased. Briefly, HIV-1 protease variants were expressed from a pXC35 Escherichia coli plasmid vector. The cell pellets were lysed and the protease was retrieved from inclusion bodies with $100 \%$ glacial acetic acid. The protease was separated from higher molecular weight proteins by size-exclusion chromatography on a Sephadex G-75 column. The purified protein was refolded by rapid dilution into a 10 -fold volume of $0.05 \mathrm{M}$ sodium acetate buffer at $\mathrm{pH}$ 5.5, containing $10 \%$ glycerol, $5 \%$ ethylene glycol, and $5 \mathrm{mM}$ dithiothreitol (refolding buffer). The tethered dimer gene construct coded for two copies of the HIV-1 monomer linked by the nucleotide sequence that codes for Gly-Gly-Ser-Ser-Gly with unique nucleotide sequences for each monomer [82, 83]. The HIV-2 PR [64] was a generous gift from Dr. John M. Louis (NIH). The theoretical isoelectric points of the viral proteases were calculated using the online ExPASy pI/MW tool.

\section{Two-substrate Proteolysis Reactions}

Two-substrate proteolysis reactions were run in proteolysis buffer $(50 \mathrm{mM}$ sodium acetate, $50 \mathrm{mM}$ NaMES, $100 \mathrm{mM}$ Tris, $2 \mathrm{mM} \beta$-mercaptoethanol, $\mathrm{pH}$ 6.5). Reactions were $150 \mu \mathrm{l}$ in volume and pre-incubated at $30^{\circ} \mathrm{C}$ for 1 hour before addition of the enzyme. The preincubation step was included for consistency, although the its primary role was to allow fluor binding in reactions that included the Lumio Green Reagent (Invitrogen). In the $\mathrm{MA} / \mathrm{CA}$ and GMC $\Delta$ reactions, both substrates began the reaction at concentrations of 2.5 $\mu \mathrm{M}$. In the MA/CA and $\mathrm{p} 15 \mathrm{NC}$ reactions, the initial concentration of MA/CA was $2.5 \mu \mathrm{M}$, while the concentration of $\mathrm{p} 15 \mathrm{NC}$ was raised to $10 \mu \mathrm{M}$ due to its poor staining profile in the subsequent analysis. The HIV-1 PR was used at a concentration of $150 \mathrm{nM}$ in the two substrate assays. RNA was also $150 \mathrm{nM}$ when present. Reaction $\mathrm{pH}$ was confirmed as 6.5 using a micro-pH electrode (Thermo Scientific) after the final time point had been collected, and was unaffected by the presence of RNA. To collect time points, $12 \mu \mathrm{l}$ aliquots were 
removed from the reactions at the indicated times and added directly to SDS to quench the reaction. The zero minute time point was removed immediately prior to the addition of enzyme. Where applicable, RNA was pre-mixed into the reaction 5 minutes prior to the removal of the zero minute time point. The quenched aliquots were loaded directly into a precast $16 \%$ Tris-Glycine gel (Invitrogen), and the substrates and products were then separated by SDS-PAGE at 100V for 2.5 hours before staining with SimplyBlue Safestain (Invitrogen). Band intensities were quantified with molecular imaging software (Carestream), and results were reported as the percent substrate remaining.

\section{Single-substrate Proteolysis Reactions}

All presented single-substrate proteolysis reactions with globular proteins were run in the proteolysis buffer. For the indicated reactions, the ionic strength was raised to $0.2 \mathrm{M}$ and 0.5 $\mathrm{M}$ by the addition of sodium chloride to a final concentration of $50 \mathrm{mM}$ and $350 \mathrm{mM}$, respectively. Select reactions for data not shown were performed in intracellular buffer (76.6 $\mathrm{mM}$ monopotassium phosphate, $60 \mathrm{mM}$ potassium hydroxide, $12 \mathrm{mM}$ sodium bicarbonate, $2.4 \mathrm{mM}$ potassium chloride, $0.8 \mathrm{mM}$ magnesium chloride, $\mathrm{pH}$ 7.2). Reaction $\mathrm{pH}$ was confirmed after collection of the final time point by a micropH electrode (Thermo Scientific). The final concentrations of MA/CA, MA/CA-AAA, and HIV-2 MA/CA were 2 $\mu \mathrm{M}$. Reaction mixtures additionally included the Lumio Green Reagent (Invitrogen) to a final concentration of $2.5 \mu \mathrm{M}$, and were pre-incubated at $30^{\circ} \mathrm{C}$ for one hour prior to initiating proteolysis. The concentration of RNA, where not directly stated, was $150 \mathrm{nM}$. Heparin and spermine were acquired from Sigma. The HIV-1 and HIV-2 PRs were used at a concentration of $100 \mathrm{nM}$ in the single-substrate assays. The tethered dimer of the HIV-1 PR was used at a concentration of $45 \mathrm{nM}$, an amount with activity equivalent to the monomeric PR in the absence of RNA. The concentrations of the remaining enzymes were adjusted so that approximately $10 \%$ of MA/CA was processed in the absence of RNA after ten minutes. Most of the other enzymes were used at concentrations similar to the HIV-1 PR (75-400 $\mathrm{nM}$ ); VEG23 and VSL23 required concentrations of $2 \mu \mathrm{M}$, however. Time points were collected, quenched, and electrophoresed as for the two-substrate assays. The fluorescently labeled proteins were imaged with a Typhoon 9000 (GE Healthcare/Amersham Biosciences), and quantified by ImageQuant TL (GE Healthcare) software. Results were reported as the percent product formed. The initial rate of the reaction was determined using only the data points collected where the reaction was $₫ 10 \%$ complete, or was estimated based on the first non-zero data point collected.

\section{Peptide Proteolysis Reactions}

Peptide proteolysis reactions were run in the peptide buffer ( $100 \mathrm{mM}$ sodium chloride, 30 $\mathrm{mM}$ sodium acetate, $\mathrm{pH}$ 4.8). The peptide utilized was HIV Protease Substrate 1 (Sigma), a 12-amino acid long peptide containing the canonical HIV-1 MA/CA cleavage site. Substrate master mixes and the PR master mix were aliquoted into separate wells of a 96-well halfarea plate (Costar) and pre-incubated in the $30^{\circ} \mathrm{C}$ reaction chamber for five minutes, during which time the background level of fluorescence was determined. A multi-channel pipet was used to simultaneously mix the HIV-1 PR into the substrate mixtures to a final concentration of $100 \mathrm{nM}$. Reactions were followed in real-time on an Envision MultiLabel Reader (PerkinElmer) for 10 minutes with time points collected every 20 seconds. When included in 
the reaction, the concentration of RNA was $400 \mathrm{nM}$. Reaction rates were calculated using the data points from only the first $10 \%$ of cleavage for each substrate concentration. To determine when $10 \%$ cleavage had occurred for each reaction, a standard curve was generated from $50 \mu \mathrm{M}$ reactions that had been run to completion and diluted to various concentrations. The values were linear from background to the upper limit of detection, a range of $0.25 \mu \mathrm{M}$ to $7 \mu \mathrm{M}$. All values necessary to follow the first $10 \%$ of each reaction fell within this range $(0.3 \mu \mathrm{M}-4 \mu \mathrm{M})$.

\section{Electrophoretic Mobility Shift Assays and Native DNA gels}

Binding reactions were $10 \mu \mathrm{l}$ in size and contained $100 \mathrm{ng}$ of ODN17 (final concentration of $\sim 2 \mu \mathrm{M})$. Protein was added to a set of reactions incrementally such that their concentration increased from $0 \mu \mathrm{M}$ to $12 \mu \mathrm{M}$. Where the mixture of nucleic acid and protein was insufficient to reach full volume, storage buffer was used. The $\mathrm{pH}$ of the binding reactions was confirmed to be 6.5 by a micropH electrode. After five minutes at room temperature, 1 $\mu \mathrm{l}$ of High-Density TBE Sample Buffer (Novex) was added. Samples were then loaded into a precast $6 \%$ DNA retardation gel (Invitrogen), and electrophoresed at 100V for 35 minutes. Gels were stained with SYBR gold (Invitrogen) according to manufacturer's instructions, and viewed with molecular imaging software (Carestream). After three five-minute washes with deionized water, the gels were stained for protein with Sypro Ruby (Invitrogen), also according to manufacturer's instructions. Results were reported as percent band intensity.

Native DNA gels were prepared similarly to the gel-shift assays, but nuclease free water was used in place of storage buffer. Additionally, no protein was present in any sample, and gels were only stained with SYBR gold. Where applicable, aliquots of the stock solutions were heated to $90^{\circ} \mathrm{C}$ for 10 minutes, then cooled rapidly by centrifugation prior to dilution. Diluting the samples before heating results in a lower retention of the higher molecular weight species.

\section{Supplementary Material}

Refer to Web version on PubMed Central for supplementary material.

\section{Acknowledgments}

We thank Dr. John M. Louis for providing the HIV-2 Protease, and Dr. Charles Carter for many helpful discussions. We also thank Dr. Nancy Cheng for assistance with the protease substrate assay. M.P. is supported, in part, by NIH Training Grant T32 AI07001. This work was supported by the NIH grant P01 GM109767. In addition, CAS, EAN and DAR were supported by NIH grant R01 GM65347, and DAR was also supported by R01 GM065347-12S1 and F31 GM111101.

\section{References}

1. Kol N, Shi Y, Tsvitov M, Barlam D, Shneck RZ, Kay MS, et al. A stiffness switch in human immunodeficiency virus. Biophys J. 2007; 92:1777-83. [PubMed: 17158573]

2. Kohl NE, Emini EA, Schleif WA, Davis LJ, Heimbach JC, Dixon RA, et al. Active human immunodeficiency virus protease is required for viral infectivity. Proc Natl Acad Sci USA. 1988; 85:4686-4690. [PubMed: 3290901]

3. Kaplan AH, Manchester M, Swanstrom R. The activity of the protease of human immunodeficiency virus type 1 is initiated at the membrane of infected cells before the release of viral proteins and is 
required for release to occur with maximum efficiency. J Virol. 1994; 68:6782-6786. [PubMed: 8084015]

4. Krausslich HG. Human immunodeficiency virus proteinase dimer as component of the viral polyprotein prevents particle assembly and viral infectivity. Proc Natl Acad Sci USA. 1991; 88:3213-3217. [PubMed: 2014242]

5. Park J, Morrow CD. Overexpression of the gag-pol precursor from human immunodeficiency virus type 1 proviral genomes results in efficient proteolytic processing in the absence of virion production. J Virol. 1991; 65:5111-5117. [PubMed: 1870215]

6. Kaplan AH, Zack JA, Knigge M, Paul DA, Kempf DJ, Norbeck DW, et al. Partial inhibition of the human immunodeficiency virus type 1 protease results in aberrant virus assembly and the formation of noninfectious particles. J Virol. 1993; 67:4050-4055. [PubMed: 8510215]

7. Moore MD, Fu W, Soheilian F, Nagashima K, Ptak RG, Pathak VK, et al. Suboptimal inhibition of protease activity in human immunodeficiency virus type 1: effects on virion morphogenesis and RNA maturation. Virology. 2008; 379:152-60. [PubMed: 18657842]

8. Muller B, Anders M, Akiyama H, Welsch S, Glass B, Nikovics K, et al. HIV-1 Gag processing intermediates trans-dominantly interfere with HIV-1 infectivity. J Biol Chem. 2009; 284:29692703. [PubMed: 19666477]

9. Bieniasz PD. The cell biology of HIV-1 virion genesis. Cell Host Microbe. 2009; 5:550-8. [PubMed: 19527882]

10. Miller M, Schneider J, Sathyanarayana BK, Toth MV, Marshall GR, Clawson L, et al. Structure of complex of synthetic HIV-1 protease with a substrate-based inhibitor at $2.3 \AA$ resolution. Science. 1989; 246:1149-1152. [PubMed: 2686029]

11. Navia MA, Fitzgerald PMD, McKeever BM, Leu C, Heimbach JC, Herber WK, et al. Threedimensional structure of aspartyl protease from human immunodeficiency virus HIV-1. Nature. 1989; 337:615-620. [PubMed: 2645523]

12. Pearl LH, Taylor WR. A structural model for retroviral proteases. Nature. 1987; 329:351-354. [PubMed: 3306411]

13. Agniswamy J, Sayer JM, Weber IT, Louis JM. Terminal interface conformations modulate dimer stability prior to amino terminal autoprocessing of HIV-1 protease. Biochemistry. 2012; 51:104150. [PubMed: 22242794]

14. Louis JM, Clore GM, Gronenborn AM. Autoprocessing of HIV-1 protease is tightly coupled to protein folding. Nat Struct Biol. 1999; 6:868-875. [PubMed: 10467100]

15. Tang C, Louis JM, Aniana A, Suh JY, Clore GM. Visualizing transient events in amino-terminal autoprocessing of HIV-1 protease. Nature. 2008; 455:693-6. [PubMed: 18833280]

16. Lindhofer H, von der Helm K, Nitschko H. In vivo processing of Pr160 gag-pol from human immunodeficiency virus type 1 (HIV) in acutely infected, cultured human T-lymphocytes. Virology. 1995; 214:624-627. [PubMed: 8553565]

17. Louis JM, Wondrak EM, Kimmel AR, Wingfield PT, Nashed NT. Proteolytic processing of HIV-1 protease precursor, kinetics and mechanism. J Biol Chem. 1999; 274:23437-23442. [PubMed: 10438521]

18. Pettit SC, Everitt LE, Choudhury S, Dunn BM, Kaplan AH. Initial cleavage of the human immunodeficiency virus type $1 \mathrm{GagPol}$ precursor by its activated protease occurs by an intramolecular mechanism. J Virol. 2004; 78:8477-85. [PubMed: 15280456]

19. Sluis-Cremer N, Arion D, Abram ME, Parniak MA. Proteolytic processing of an HIV-1 pol polyprotein precursor: insights into the mechanism of reverse transcriptase p66/p51 heterodimer formation. Int J Biochem Cell Biol. 2004; 36:1836-47. [PubMed: 15183348]

20. Pettit SC, Clemente JC, Jeung JA, Dunn BM, Kaplan AH. Ordered processing of the human immunodeficiency virus type $1 \mathrm{GagPol}$ precursor is influenced by the context of the embedded viral protease. J Virol. 2005; 79:10601-7. [PubMed: 16051852]

21. Wondrak EM, Louis JM. Influence of flanking sequences on the dimer stability of human immunodeficiency virus type 1 protease. Biochemistry. 1996; 35:12957-12962. [PubMed: 8841142] 
22. Erickson-Viitanen S, Manfredi J, Viitanen P, Tribe DE, Tritch R, Hutchison CA III, et al. Cleavage of HIV-1 gag polyprotein synthesized in vitro: sequential cleavage by the viral protease. AIDS Res Hum Retrov. 1989; 5:577-591.

23. Pettit SC, Moody MD, Wehbie RS, Kaplan AH, Nantermet PV, Klein CA, et al. The p2 domain of human immunodeficiency virus type 1 gag regulates sequential proteolytic processing and is required to produce fully infectious virions. J Virol. 1994; 68:8017-8027. [PubMed: 7966591]

24. Wiegers K, Rutter G, Kottler H, Tessmer U, Hohenberg H, Krausslich HG. Sequential steps in human immunodeficiency virus particle maturation revealed by alterations of individual gag polyprotein cleavage sites. J Virol. 1998; 72:2846-2854. [PubMed: 9525604]

25. Checkley MA, Luttge BG, Soheilian F, Nagashima K, Freed EO. The capsid-spacer peptide 1 Gag processing intermediate is a dominant-negative inhibitor of HIV-1 maturation. Virology. 2010; 400:137-44. [PubMed: 20172577]

26. Lee SK, Harris J, Swanstrom R. A strongly transdominant mutation in the human immunodeficiency virus type 1 gag gene defines an Achilles heel in the virus life cycle. J Virol. 2009; 83:8536-43. [PubMed: 19515760]

27. Rulli SJ Jr, Muriaux D, Nagashima K, Mirro J, Oshima M, Baumann JG, et al. Mutant murine leukemia virus Gag proteins lacking proline at the N-terminus of the capsid domain block infectivity in virions containing wild-type Gag. Virology. 2006; 347:364-71. [PubMed: 16427108]

28. Pettit SC, Simsic J, Loeb DD, Everitt LE, Hutchison CA III, Swanstrom R. Analysis of retroviral protease cleavage sites reveals two types of cleavage sites and the structural requirements of the P1 amino acid. J Biol Chem. 1991; 266:14539-14547. [PubMed: 1860860]

29. Ozen A, Haliloglu T, Schiffer CA. Dynamics of preferential substrate recognition in HIV-1 protease: redefining the substrate envelope. J Mol Biol. 2011; 410:726-44. [PubMed: 21762811]

30. Prabu-Jeyabalan M, Nalivaika E, Schiffer CA. Substrate shape determines specificity of recognition for HIV-1 protease: analysis of crystal structures of six substrate complexes. Structure. 2002; 10:369-381. [PubMed: 12005435]

31. Deshmukh L, Ghirlando R, Clore GM. Conformation and dynamics of the Gag polyprotein of the human immunodeficiency virus 1 studied by NMR spectroscopy. Proc Natl Acad Sci USA. 2015

32. Lee SK, Potempa M, Kolli M, Ozen A, Schiffer CA, Swanstrom R. Context surrounding processing sites is crucial in determining cleavage rate of a subset of processing sites in HIV-1 Gag and Gag-Pro-Pol polyprotein precursors by viral protease. J Biol Chem. 2012; 287:13279-90. [PubMed: 22334652]

33. Tritch R, Cheng YE, Yin FH, Erickson-Viitanen S. Mutagenesis of protease cleavage sites in the human immunodeficiency virus type 1 gag polyprotein. J Virol. 1991; 65:922-930. [PubMed: 1987379]

34. Mirambeau G, Lyonnais S, Coulaud D, Hameau L, Lafosse S, Jeusset J, et al. HIV-1 protease and reverse transcriptase control the architecture of their nucleocapsid partner. PLoS One. 2007; 2:e669. [PubMed: 17712401]

35. Sheng N, Erickson-Viitanen S. Cleavage of p15 protein in vitro by human immunodefiency virus type 1 protease is RNA dependent. J Virol. 1994; 68:6207-6214. [PubMed: 8083960]

36. Sheng N, Pettit SC, Tritch R, Ozturk DH, Rayner MM, Swanstrom R, et al. Determinants of the human immunodeficiency virus type 1 p15NC-RNA interaction that affect enhanced cleavage by the viral protease. J Virol. 1997; 71:5723-5732. [PubMed: 9223458]

37. Dorfman T, Bukovsky A, Ohagen A, Hoglund S, Gottlinger HG. Functional domains of the capsid protein of human immunodefiency virus type 1. J Virol. 1994; 68:8180-8187. [PubMed: 7966609]

38. Momany C, Kovari LC, Prongay AJ, Keller W, Gitti RK, Lee BM, et al. Crystal structure of dimeric HIV-1 capsid protein. Nat Struct Biol. 1996; 3:763-770. [PubMed: 8784350]

39. Porter DJT, Hanlon MH, Carter LH III, Danger DP, Furfine ES. Effectors of HIV-1 protease peptidolytic activity. Biochemistry. 2001; 40:11131-11139. [PubMed: 11551211]

40. Alfadhli A, McNett H, Tsagli S, Bachinger HP, Peyton DH, Barklis E. HIV-1 matrix protein binding to RNA. J Mol Biol. 2011; 410:653-66. [PubMed: 21762806]

41. Chukkapalli V, Oh SJ, Ono A. Opposing mechanisms involving RNA and lipids regulate HIV-1 Gag membrane binding through the highly basic region of the matrix domain. Proc Natl Acad Sci USA. 2010; 107:1600-5. [PubMed: 20080620] 
42. Lochrie MA, Waugh S, Pratt DG Jr, Clever J, Parslow TG, Polisky B. In vitro selection of RNAs that bind to the human immunodeficiency virus type-1 gag polyprotein. Nucleic Acids Res. 1997; 25:2902-2910. [PubMed: 9207041]

43. Ott DE, Coren LV, Gagliardi TD. Redundant roles for nucleocapsid and matrix RNA-binding sequences in human immunodeficiency virus type 1 assembly. J Virol. 2005; 79:13839-47. [PubMed: 16254319]

44. Purohit P, Dupont S, Stevenson M, Green MR. Sequence-specific interaction between HIV-1 matrix protein and viral genomic RNA revealed by in vitro genetic selection. RNA. 2001; 7:576584. [PubMed: 11345436]

45. Lyonnais S. G-quartets direct assembly of HIV-1 nucleocapsid protein along single-stranded DNA. Nucleic Acids Res. 2003; 31:5754-5763. [PubMed: 14500839]

46. Gueron M, Leroy J. The i-motif in nucleic acids. Curr Opin Struct Biol. 2000; 10:326-331. [PubMed: 10851195]

47. Deutsch C, Taylor JS, Wilson DF. Regulation of intracellular $\mathrm{pH}$ by human peripheral blood lymphocytes as measured by ${ }^{19}$ F NMR. Proc Natl Acad Sci USA. 1982; 79:7944-7948. [PubMed: 6961462]

48. Darke PL, Jordan SP, Hall DL, Zugay JA, Shafer JA, Kuo LC. Dissociation and association of the HIV-1 protease dimer subunits: equilibria and rates. Biochemistry. 1994; 33:98-105. [PubMed: 8286367]

49. Copeland, RA. Cooperativity in enzyme catalysis. In: Copeland, RA., editor. Enzymes: a practical introduction to structure, mechanism, and data analysis. Second. New York, NY, USA: WileyVCH; 2000. p. 367-384.

50. Blainey PC, Graziano V, Perez-Berna AJ, McGrath WJ, Flint SJ, San Martin C, et al. Regulation of a viral proteinase by a peptide and DNA in one-dimensional space: IV. viral proteinase slides along DNA to locate and process its substrates. J Biol Chem. 2013; 288:2092-102. [PubMed: 23043138]

51. Mangel WF, McGrath WJ, Toledo DL, Anderson CW. Viral DNA and a viral peptide can act as cofactors of adenovirus virion proteinase activity. Nature. 1993; 361:274-275. [PubMed: 8423855]

52. McGrath WJ, Baniecki ML, Li C, McWhirter SM, Brown MT, Toledo DL, et al. Human adenovirus proteinase: DNA binding and stimulation of proteinase activity by DNA. Biochemistry. 2001; 40:13237-13245. [PubMed: 11683632]

53. Hartl MJ, Bodem J, Jochheim F, Rethwilm A, Rosch P, Wohrl BM. Regulation of foamy virus protease activity by viral RNA: a novel and unique mechanism among retroviruses. J Virol. 2011; 85:4462-9. [PubMed: 21325405]

54. Beran RK, Serebrov V, Pyle AM. The serine protease domain of hepatitis C viral NS3 activates RNA helicase activity by promoting the binding of RNA substrate. J Biol Chem. 2007; 282:34913-20. [PubMed: 17921146]

55. Ray U, Das S. Interplay between NS3 protease and human La protein regulates translationreplication switch of Hepatitis C virus. Sci Rep. 2011; 1:1. [PubMed: 22355520]

56. Chakraborty S, Sharma S, Maiti PK, Krishnan Y. The poly dA helix: a new structural motif for high performance DNA-based molecular switches. Nucleic Acids Res. 2009; 37:2810-7. [PubMed: 19279188]

57. Rich A, Davies DR, Crick FHC, Watson JD. The molecular structure of polyadenylic acid. J Mol Biol. 1961; 3:71-86. [PubMed: 13741242]

58. Zimmerman SB, Davies DR, Navia MA. An ordered single-stranded structure for polyadenylic acid in denaturing solvents. An X-ray fiber diffraction and model building study. J Mol Biol. 1977; 116:317-330. [PubMed: 599560]

59. Drummond JE, Mounts P, Gorelick RJ, Casas-Finet JR, Bosche WJ, Henderson LE, et al. Wildtype and mutant HIV type 1 nucelocapsid proteins increase the proportion of long cDNA transcripts by viral reverse transcriptase. AIDS RES HUM RETROV. 1997; 13:533-543.

60. Khan R, Giedroc DP. Nucleic acid binding properties of recombinant Zn2 HIV-1 nucleocapsid protein are modulated by COOH-terminal processing. J Biol Chem. 1994; 269:22538-22546. [PubMed: 8077202] 
61. Chen Z, Li Y, Chen E, Hall DL, Darke PL, Culberson C, et al. Crystal structure at 1.9-A resolution of human immunodeficiency virus (HIV) II protease complexed with L-735,524, an orally bioavailable inhibitor of the HIV proteases. J Biol Chem. 1994; 269:26344-26348. [PubMed: 7929352]

62. Gustchina A, Weber IT. Comparative analysis of the sequences and structures of HIV-1 and HIV-2 proteases. Proteins. 1991; 10:325-339. [PubMed: 1946342]

63. Kovalevsky AY, Louis JM, Aniana A, Ghosh AK, Weber IT. Structural evidence for effectiveness of darunavir and two related antiviral inhibitors against HIV-2 protease. J Mol Biol. 2008; 384:178-92. [PubMed: 18834890]

64. Louis JM, Ishima R, Aniana A, Sayer JM. Revealing the dimer dissociation and existence of a folded monomer of the mature HIV-2 protease. Protein Sci. 2009; 18:2442-53. [PubMed: 19798742]

65. Pichuantes S, Babe LM, Barr PJ, DeCamp DL, Craik CS. Recombinant HIV2 protease processes HIV1 Pr53 ${ }^{\text {gag }}$ and analogous junction peptides in vitro. J Biol Chem. 1990; 265:13890-13898. [PubMed: 2199446]

66. Tozser J, Blaha I, Copeland TD, Wondrak EM, Oroszlan S. Comparison of the HIV-1 and HIV-2 proteinases using oligopeptide substrates representing cleavage sites in gag and gag-pol polyproteins. FEBS. 1991; 281:77-80.

67. Motorin Y, Helm M. tRNA stabilization by modified nucleotides. Biochemistry. 2010; 49:493444. [PubMed: 20459084]

68. Alderfer JL, Smith SL. A proton magnetic resonance study of polydeoxyriboadenylic acid. J Am Chem Soc. 1971; 93:7305-7314. [PubMed: 5127420]

69. Ke C, Humeniuk M, S-Gracz H, Marszalek PE. Direct Measurements of Base Stacking Interactions in DNA by Single-Molecule Atomic-Force Spectroscopy. Phys Rev Lett. 2007; 99

70. Cheng YE, Yin FH, Foundling S, Blomstrom D, Kettner CA. Stability and activity of human immunodeficiency virus protease: comparison of the natural dimer with a homologous, singlechain tethered dimer. Proc Natl Acad Sci USA. 1990; 87:9660-9664. [PubMed: 2263618]

71. Judd DA, Nettles JH, Nevins N, Snyder JP, Liotta DC, Tang J, et al. Polyoxometalate HIV-1 protease inhibitors. A new mode of protease inhibition. J Am Chem Soc. 2001; 123:886-897. [PubMed: 11456622]

72. Sperka T, Pitlik J, Bagossi P, Tozser J. Beta-lactam compounds as apparently uncompetitive inhibitors of HIV-1 protease. Bioorg Med Chem Lett. 2005; 15:3086-90. [PubMed: 15893929]

73. Ung PM, Dunbar JB Jr, Gestwicki JE, Carlson HA. An allosteric modulator of HIV-1 protease shows equipotent inhibition of wild-type and drug-resistant proteases. J Med Chem. 2014; 57:6468-78. [PubMed: 25062388]

74. Kovalevsky AY, Liu F, Leshchenko S, Ghosh AK, Louis JM, Harrison RW, et al. Ultra-high resolution crystal structure of HIV-1 protease mutant reveals two binding sites for clinical inhibitor TMC 114. J Mol Biol. 2006; 363:161-73. [PubMed: 16962136]

75. Baca M, Kent SBH. Catalytic contribution of flap-substrate hydrogen bonds in "HIV-1 protease" explored by chemical synthesis. Proc Natl Acad Sci USA. 1993; 90:11638-11642. [PubMed: 8265601]

76. Torbeev VY, Raghuraman H, Hamelberg D, Tonelli M, Westler WM, Perozo E, et al. Protein conformational dynamics in the mechanism of HIV-1 protease catalysis. Proc Natl Acad Sci USA. 2011; 108:20982-7. [PubMed: 22158985]

77. Freedberg DI, Ishima R, Jacob J, Wang YX, Kustanovich I, Louis JM, et al. Rapid structural fluctuations of the free HIV protease flaps in solution: relationship to crystal structures and comparison with predictions of dynamics calculations. Protein Sci. 2002; 11:221-32. [PubMed: 11790832]

78. Karthik S, Senapati S. Dynamic flaps in HIV-1 protease adopt unique ordering at different stages in the catalytic cycle. Proteins. 2011; 79:1830-40. [PubMed: 21465560]

79. Scott WRP, Schiffer CA. Curling of flap tips in HIV-1 protease as a mechanism for substrate entry and tolerance of drug resistance. Structure. 2000; 8:1259-1265. [PubMed: 11188690] 
80. Torbeev VY, Raghuraman H, Mandal K, Senapati S, Perozo E, Kent SBH. Dynamics of "flap" structures in three HIV-1 protease/inhibitor complexes probed by total chemical synthesis and pulse-EPR spectroscopy. J Am Chem Soc. 2009; 131

81. Prabu-Jeyabalan M, Nalivaika E, Schiffer CA. How does a symmetric dimer recognize an asymmetric substrate? A substrate complex of HIV-1 protease. J Mol Biol. 2000; 301:1207-20. [PubMed: 10966816]

82. Alvizo O, Mittal S, Mayo SL, Schiffer CA. Structural, kinetic, and thermodynamic studies of specificity designed HIV-1 protease. Protein Sci. 2012; 21:1029-41. [PubMed: 22549928]

83. Bhat TN, Baldwin ET, Liu B, Cheng YE, Erickson JW. Crystal structure of a tethered dimer of HIV-1 proteinase complexed with an inhibitor. Nat Struct Biol. 1994; 1:552-556. [PubMed: 7664084]

84. Surleraux DLN, Tahri A, Verschueren WG, Pille GME, de Kock HA, Jonckers TMH, et al. Discovery and selection of TMC114, a next generation HIV-1 protease inhibitor. J Med Chem. 2005; 48:1813-1822. [PubMed: 15771427]

\section{Abbreviations}

$\begin{array}{ll}\text { HIV } & \text { human immunodeficiency virus } \\ \text { PR } & \text { protease } \\ \text { AVP } & \text { adenovirus proteinase } \\ \text { PFV } & \text { prototype foamy virus } \\ \text { NS3 } & \text { non-structural protein } 3 \text { serine protease }\end{array}$

MA matrix

CA capsid

NC nucleocapsid

SP1/2 $\quad$ spacer peptide $1 / 2$ 


\section{Research Highlights}

- The mechanisms regulating HIV-1 protease (PR) activity are poorly understood.

- $\quad$ RNA accelerates cleavage of multiple substrates, regardless of RNA-binding ability.

- The HIV-1 PR can interact with nucleic acid to increase its catalytic efficiency.

- The interaction is primarily electrostatic, but size/structural determinants exist.

- Interactions between the HIV-1 PR and RNA could affect PR activity in the virion. 
(a)

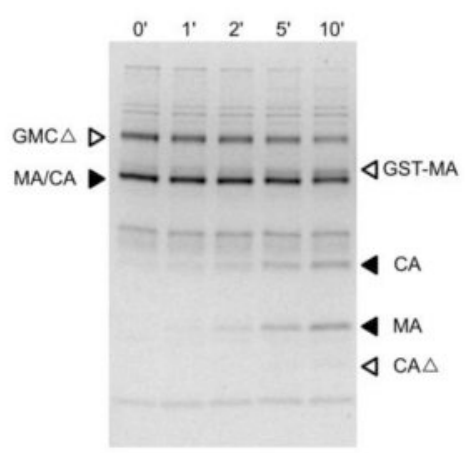

(c)

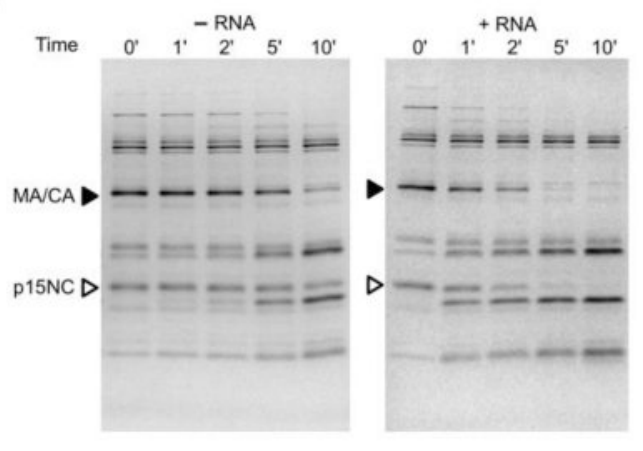

(b)

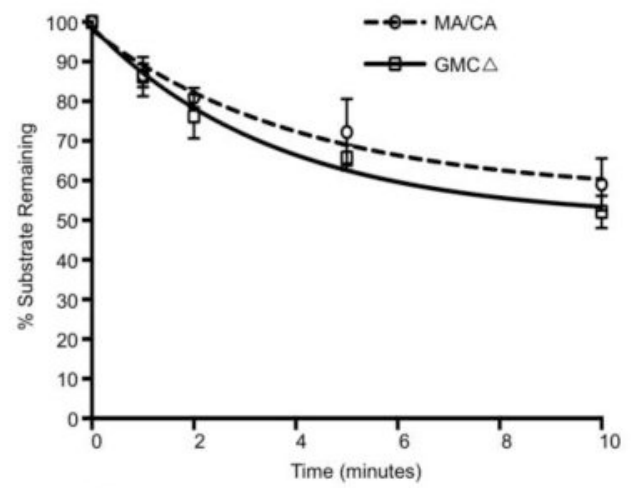

(d)

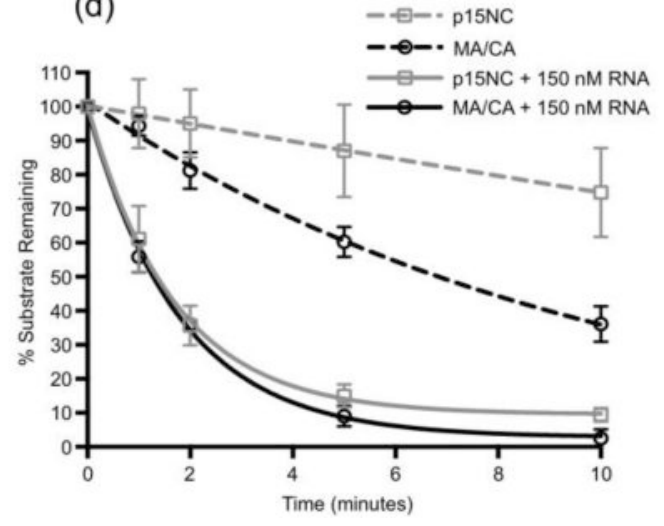

Figure 1.

Concomitant processing of multiple substrates by the HIV-1 protease. (a) A reaction mixture containing the MA/CA (solid triangle) and GMC $\Delta$ (open triangle) substrates in equimolar amounts was incubated at $30^{\circ} \mathrm{C}, \mathrm{pH} 6.5$ for 1 hour prior to the addition of the HIV-1 PR.

Reactions were run for 10 minutes with the intermittent removal of aliquots that were immediately mixed with SDS to halt the reaction. Reaction substrates and products were separated by SDS-PAGE and stained by coomassie. MA/CA products are indicated with solid, reversed triangles; GMC $\Delta$ products with open, reversed triangles. (b) MA/CA (circle) and GMC $\Delta$ (square) bands were quantified with imaging software and graphed as substrate remaining versus time. (c) Reactions containing MA/CA (solid triangle) and p15NC (open triangle) in a molar ratio of 1:4 were performed as in Figure 1a, $+/-150 \mathrm{nM}$ of a heteropolymeric 532-nucleotide RNA derived from the p15NC region of the HIV-1 NL4-3 genome. (d) Quantification of MA/CA (black circle) and p15NC (grey square) two-substrate assays. Dashed lines show reactions without RNA; reactions with RNA are represented with solid lines. All errors bars represent the standard deviation resulting from three independent experiments. 
(a)

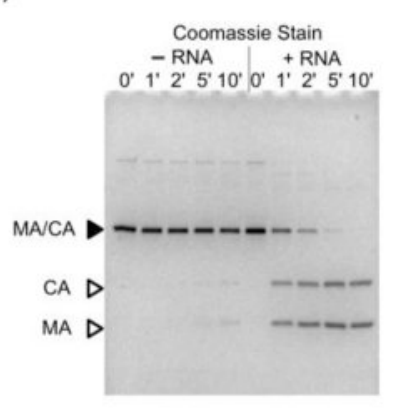

(c)

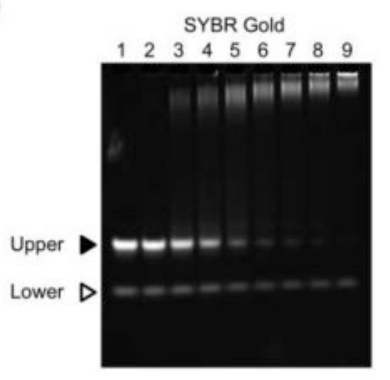

(d)

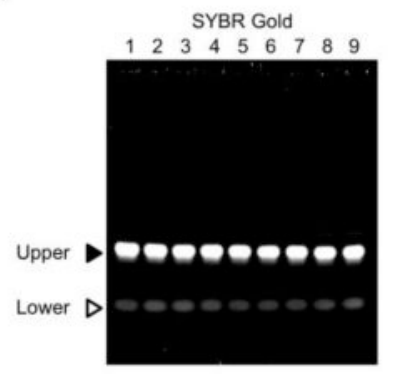

(b)
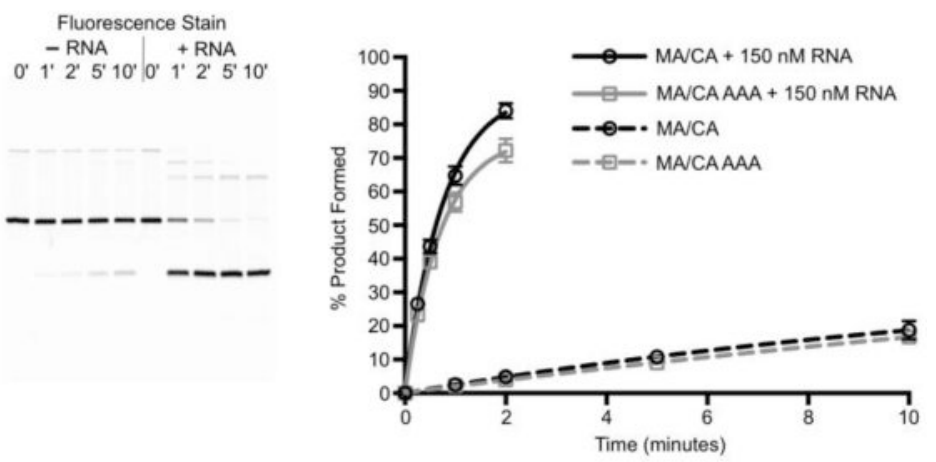

SYPRO Ruby
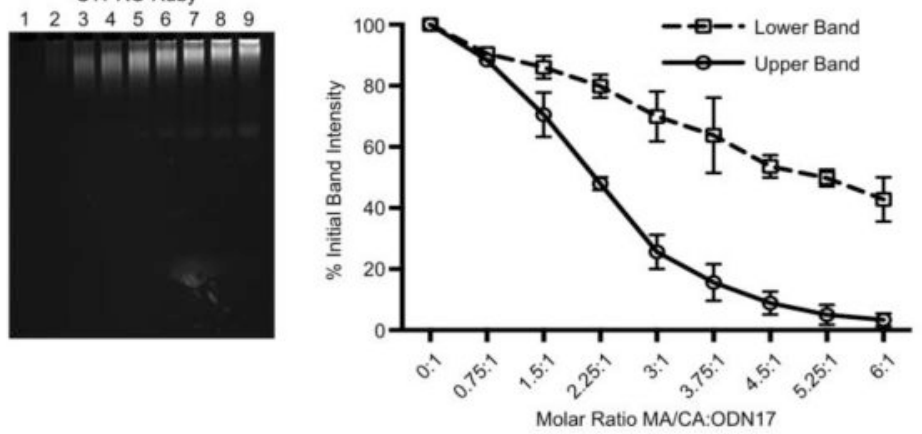

SYPRO Ruby

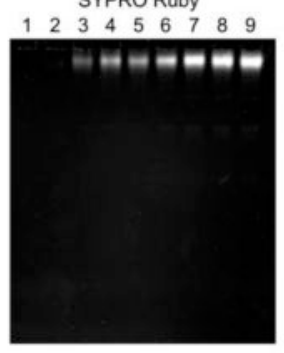

Figure 2.

RNA accelerates processing independent of the ability of MA/CA to bind nucleic acid. (a) $\mathrm{MA} / \mathrm{CA}$ proteins were tagged with the Lumio Green Reagent via mutation of the Cyclophilin A binding loop in CA to include a CCPGCC motif. Single-substrate MA/CA proteolysis assays were visualized by coomassie (left) and fluorescence (right). Only CAcontaining reactant and product species are present in the fluorescence stain. (b) Reaction progress curves for single-substrate MA/CA (black) and MA/CA-AAA (grey) proteolysis reactions performed in the absence (dashed lines) and presence (solid lines) of RNA. (c) and (d) Binding reactions containing $100 \mathrm{ng}(2 \mu \mathrm{M})$ of the single-stranded DNA molecule ODN17 and steadily increasing amounts (from $0 \mu \mathrm{M}$ in lane 1 to $12 \mu \mathrm{M}$ in lane 9) of MA/CA (c) or MA/CA-AAA (d) were electrophoresed in a $6 \%$ polyacrylamide gel under native conditions. Gels were stained with SYBR Gold (left panel) to visualize nucleic acid species. The gels were then washed and restained with SYPRO Ruby (central panel) to view protein. The intensity of each nucleic acid species relative to the respective band in the no- 
protein reaction (lane 1) was determined by densitometry and plotted as a function of protein:ODN17 concentration (right panel). All errors bars represent the standard deviation resulting from three independent experiments. 


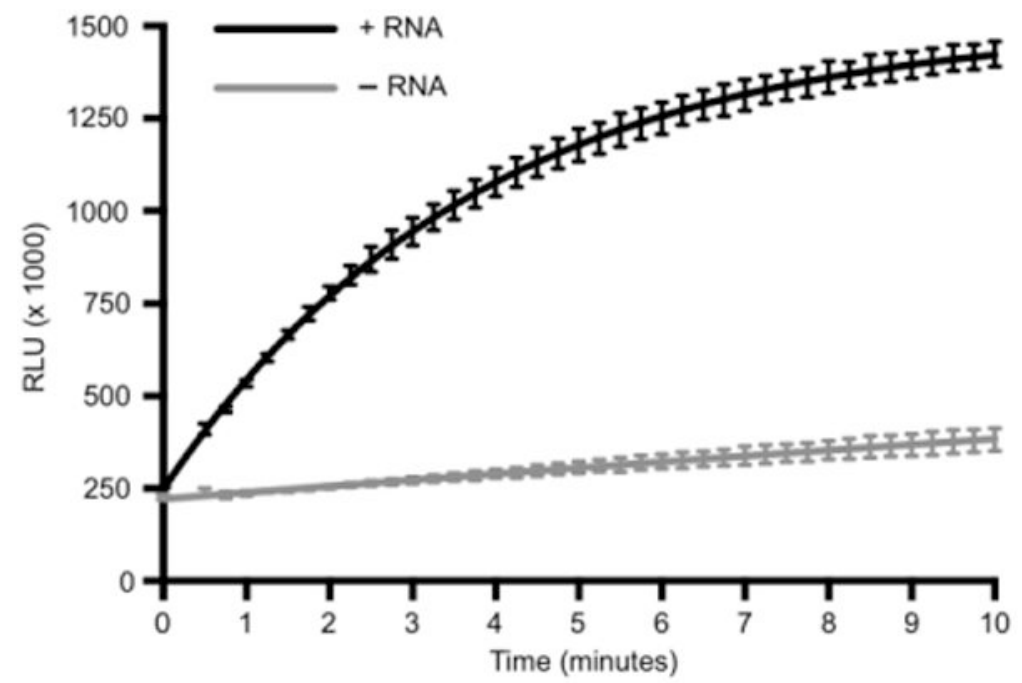

Figure 3.

The addition of RNA to a reaction accelerates processing of a peptide substrate. A commercially available 12-amino acid peptide substrate was utilized as a substrate for the HIV-1 PR. Processing of the peptide substrate was monitored by an increase in fluorescence resulting from the separation of a fluorophore from a quencher placed on opposing ends of the peptide. Reactions were run at $30^{\circ} \mathrm{C}, \mathrm{pH} 4.8$, and performed in the absence (grey) or presence (black) of long, heteropolymeric RNA. All errors bars represent the standard deviation resulting from three independent experiments. 


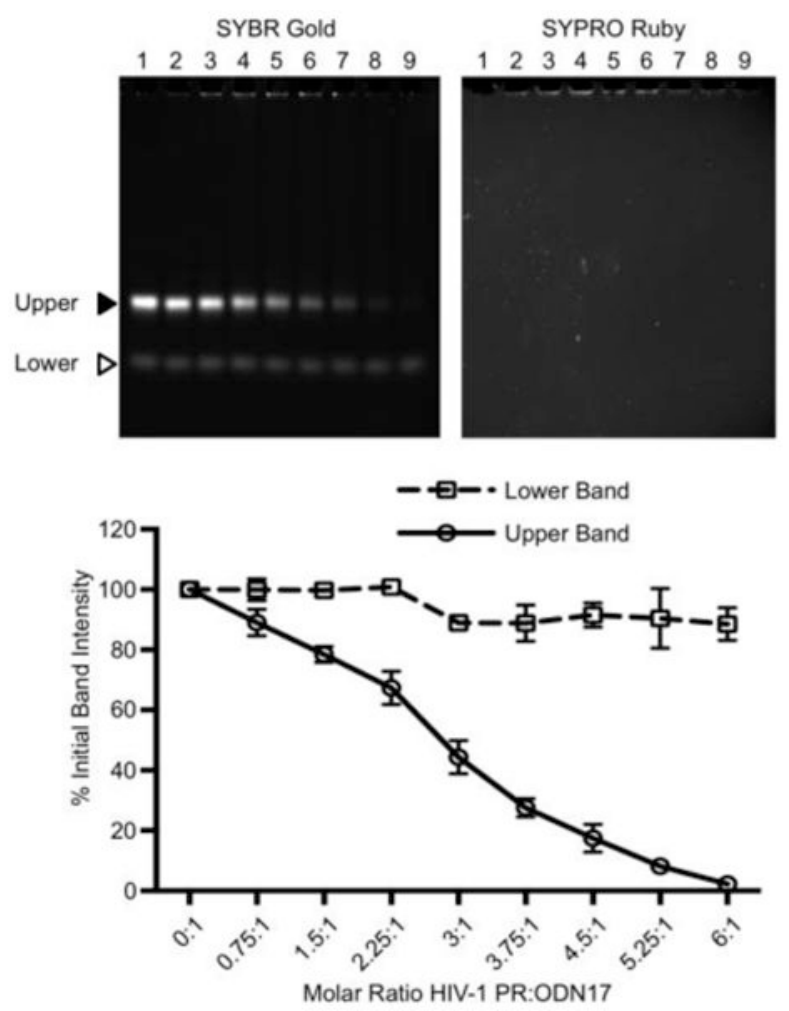

Figure 4.

The HIV-1 PR can directly interact with nucleic acid. Binding reactions containing $100 \mathrm{ng}$ of ODN17 $(2 \mu \mathrm{M})$ and steadily increasing amounts (from $0 \mu \mathrm{M}$ in lane 1 to $12 \mu \mathrm{M}$ in lane 9) of the HIV-1 PR were electrophoresed in a $6 \%$ polyacrylamide gel under native conditions. As previously, gels were stained with SYBR Gold (top left) to visualize the nucleic acid species followed by SYPRO Ruby (top right) for visualization of protein. The relative intensity of each nucleic acid species was determined by densitometry and plotted as a function of protein:ODN17 concentration (bottom). The HIV-1 PR does not enter the gel under native conditions because of its high isoelectric point $(\mathrm{pI}=9.1)$. Complexes can be inferred from the low level fluorescence present in the wells of the central lanes and the selective depletion of the upper nucleic acid species. All errors bars represent the standard deviation resulting from three independent experiments. 


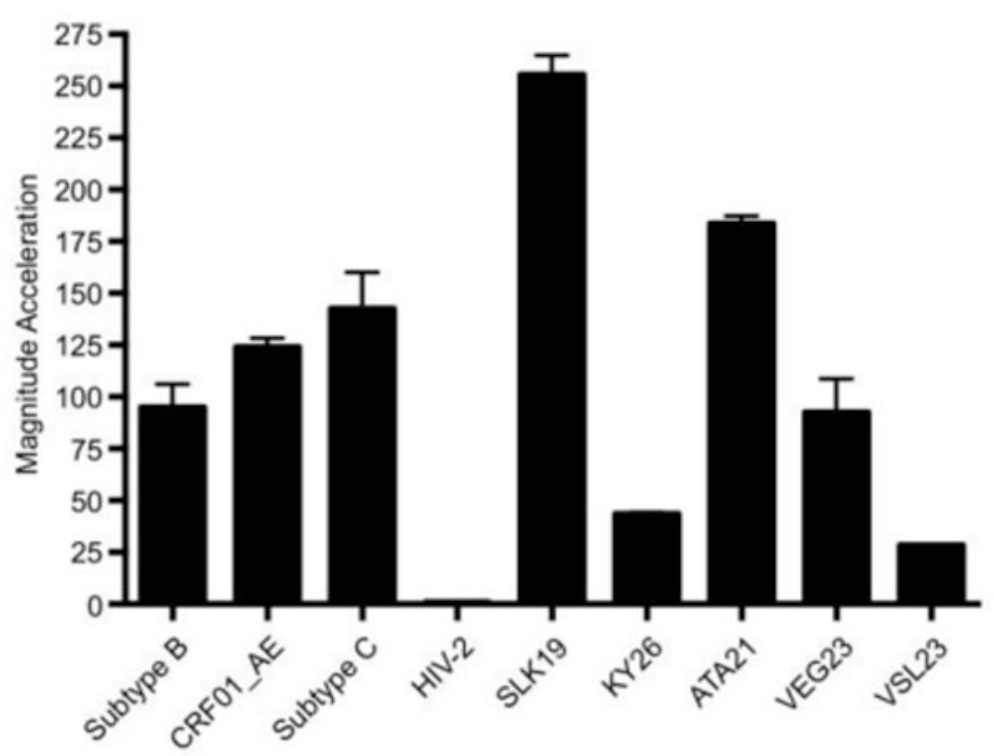

Figure 5.

The rate of processing by multiple HIV-1 PRs, but not the HIV-2 PR, increases in the presence of RNA. The rate of MA/CA processing by HIV-1 PRs from three different subtypes and an HIV-2 PR were evaluated in the presence and absence of RNA. The MA/CA protein substrate for the HIV-2 PR was mutated at the processing site to better reflect the canonical HIV-2 MA/CA processing site. Five highly mutated drug-resistant HIV-1 subtype B PRs (SLK19, KY26, ATA21, VEG23, and VSL23) were also examined. Reactions were performed with the globular MA/CA substrate under standard conditions with the exception of PR concentration, which was adjusted on an enzyme-to-enzyme basis to achieve $10 \%$ cleavage over the course of the reaction in the absence of RNA. SLK19, KY26, and ATA21 required up to 4-fold higher concentrations; VEG23 and VSL23 were more severely attenuated, and required a 20-fold higher concentration of enzyme. Results are reported as the magnitude difference in acceleration of the RNA-plus reaction relative to each enzyme's respective no-RNA control. All errors bars represent the standard deviation resulting from three independent experiments. 
(a)

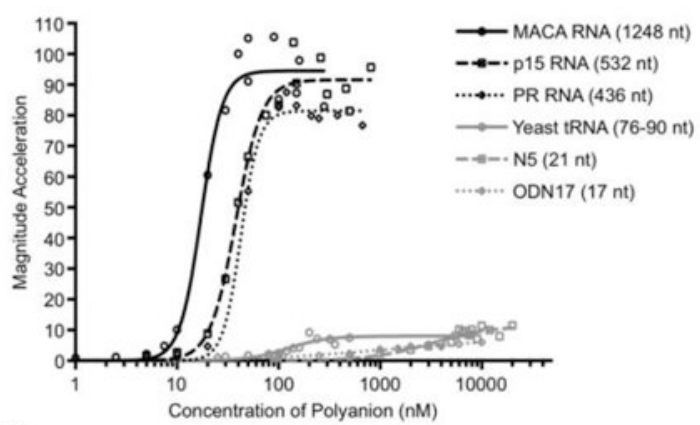

(b)

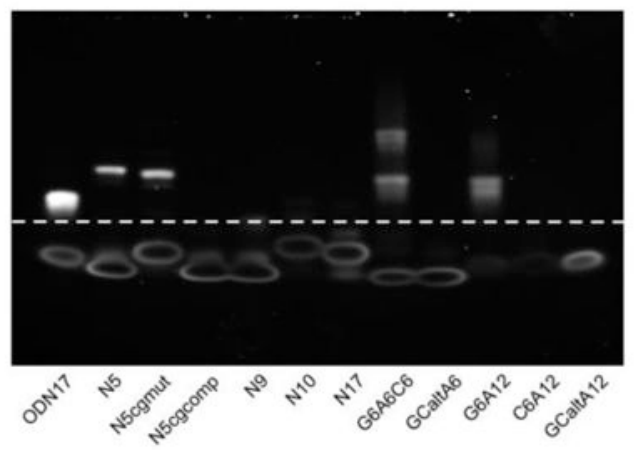

(c)

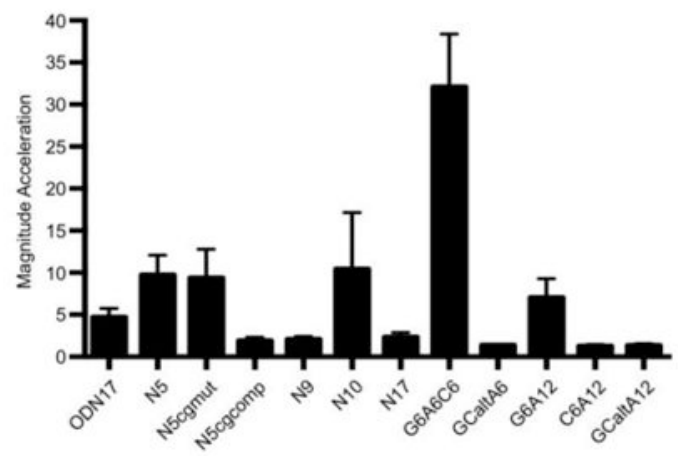

Figure 6.

Multiple nucleic acid species can enhance HIV-1 PR activity, though potencies vary. (a) Dose response curves were generated for several long heteropolymeric RNAs, yeast tRNA, and the single-stranded DNA oligonucleotides N5 and ODN17. Reactions were performed under standard conditions using the MA/CA protein as the substrate. (b) $100 \mathrm{ng}$ of the indicated single-stranded DNA oligonucleotides were electrophoresed in a $6 \%$ polyacrylamide gel under nondenaturing conditions, and then visualized with SYBR gold. The dashed white line distinguishes single-stranded species from oligomeric species. (c) Each single-stranded DNA oligonucleotide was supplied at a final concentration of $10 \mu \mathrm{M}$ in MA/CA processing reactions and evaluated for its ability to improve HIV-1 PR function. Results are reported as the magnitude of acceleration relative to MA/CA processing in the absence of nucleic acid. All errors bars represent the standard deviation resulting from three independent experiments. 
(a)

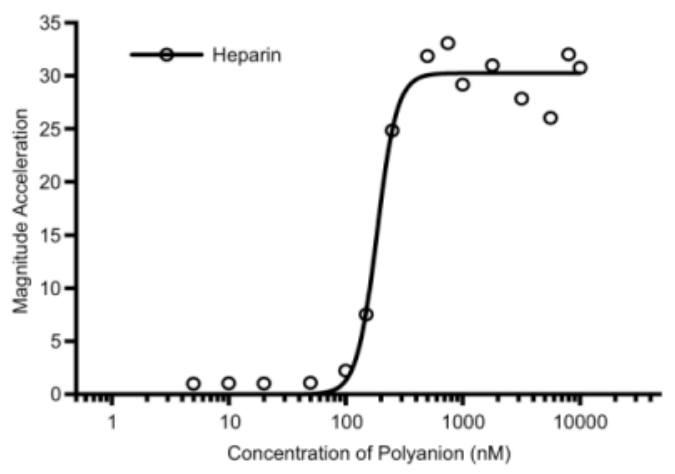

(b)

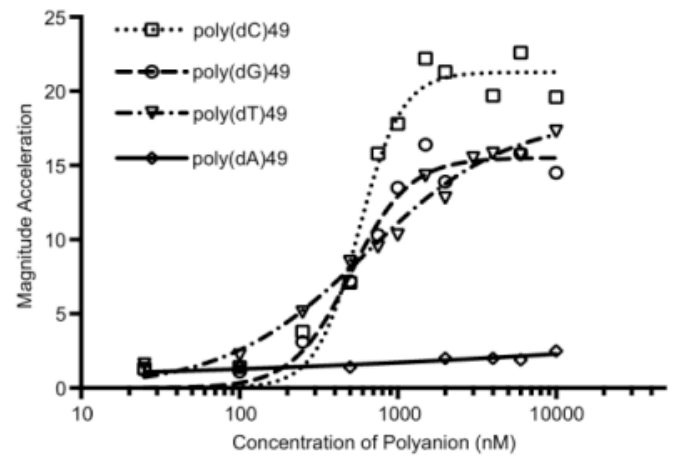

Figure 7.

A specific nucleic acid sequence or structure is not required for enhancement. Doseresponse curves were generated under standard assay conditions for (a) heparin, and (b) deoxynucleotide homopolymers. Reactions were performed with the globular MA/CA substrate under standard conditions. 


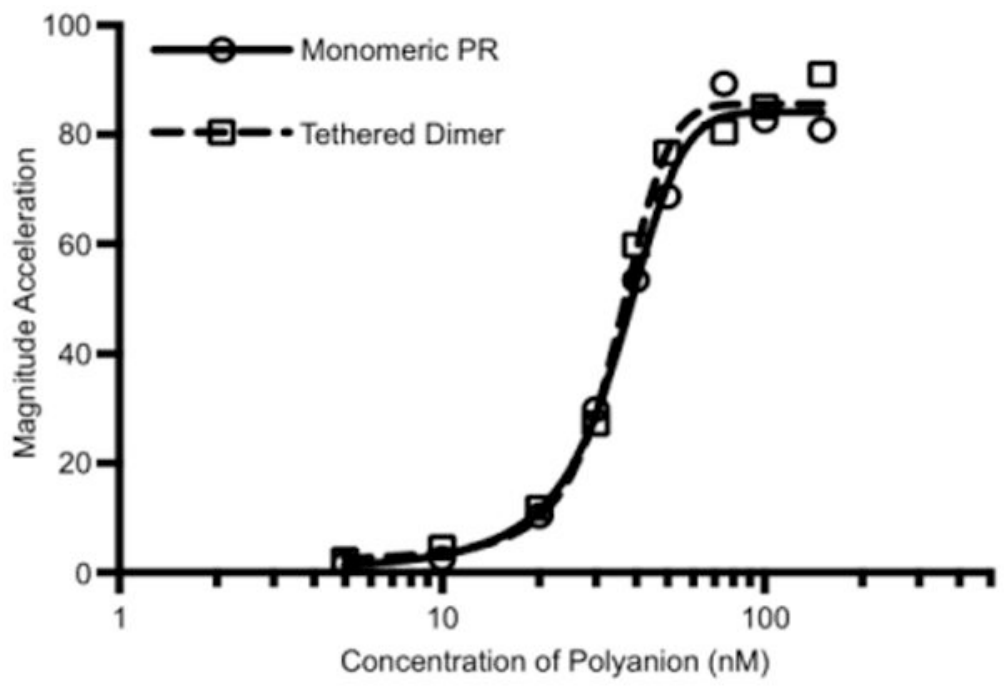

Figure 8.

RNA acts on the dimeric form of the HIV-1 PR to accelerate MA/CA processing. Dose response curves were created to compare the ability of RNA to enhance the activity of the monomeric HIV-1 PR (circle) and a tethered dimer of the HIV-1 PR (square). Reactions were performed with the globular MA/CA substrate under standard conditions except that the concentration of the tethered PR dimer was reduced to reflect its pre-existing dimerized state. 


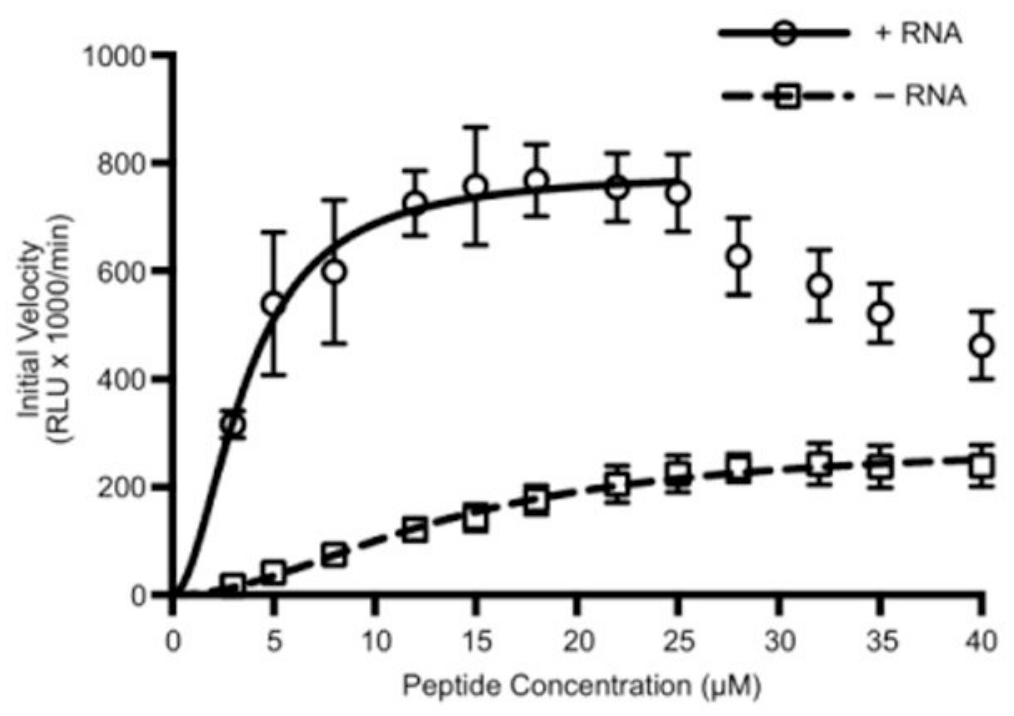

Figure 9.

Both the affinity of the HIV-1 PR for a peptide substrate and reaction turnover number increase in the presence of RNA. Peptide proteolysis reactions were prepared where the concentration of peptide was varied from 3 to $40 \mu \mathrm{M}$. Reaction progress curves were generated for each reaction. The initial velocity of each reaction was determined from the reaction progress curves and plotted as a function of peptide concentration in the absence (square) or presence (circle) of $400 \mathrm{nM}$ long heteropolymeric RNA. At higher peptide concentrations, substrate began outcompeting the HIV-1 PR for binding to the RNA, resulting in reduced initial velocity values. These data points ( $27 \mu \mathrm{M}$ and above) were excluded from the plus-RNA curve in the calculation of $\mathrm{Km}$ and Vmax. Each point on the curve was calculated twice, with each calculation the result of reactions run in triplicate (i.e. six total reactions per point). Error bars represent the difference in the pair of calculated initial velocity measurements. 


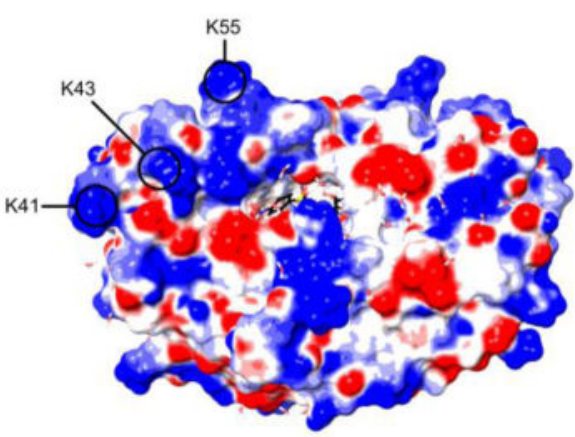

HIV-1 Protease

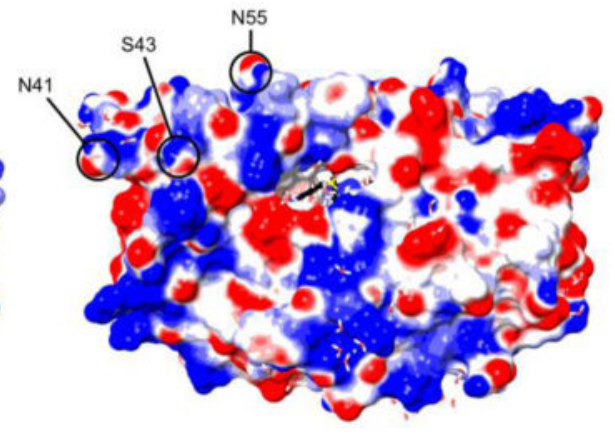

HIV-2 Protease

\section{Figure 10.}

Electrostatic potential of the HIV-1 and HIV-2 PRs. Positively charged regions on the surface of the HIV-1 PR (left, PDB: 1T3R) and HIV-2 PR (right, PDB: 3EBZ) are shown in blue; negatively charged regions are shown in red. Both structures were generated in the presence of darunavir $[63,84]$. The flap region of the HIV-1 PR appears to have a basic profile, while the flaps of the HIV-2 PR are of a mixed composition. Highlighted are three amino acid positions (41, 43 [71], and 55 [71, 74]) involved in binding interactions with putative non-active site inhibitors of the HIV-1 PR, which carry a positive charge in the HIV-1 PR but not the HIV-2 PR. 
Table 1

Length and efficacy of polyanions as enhancers of HIV-1 PR activity.

\begin{tabular}{ccccc}
\hline & Length (nt) & Max. Fold Acceleration & EC50 (nM) & EC50/nt (nt × 10^18/L) \\
\hline MACA RNA & 1248 & 95 & 17 & 13 \\
p15 RNA & 532 & 92 & 38 & 12 \\
PR RNA & 436 & 82 & 43 & 11 \\
Yeast tRNA & $76-90$ & 8.0 & $108-124$ & $5.7-6.7$ \\
N5 & 21 & 12 & 3229 & 41 \\
ODN17 & 17 & 7.3 & 1148 & 12 \\
\hline \multirow{2}{*}{ Heparin } & --- & 30 & $175-195$ & --- \\
\hline Poly(dA) & 49 & $<2$ & --- & --- \\
Poly(dC) & 49 & 21 & 569 & 17 \\
Poly(dG) & 49 & 15 & 506 & 15 \\
Poly(dT) & 49 & 18 & 635 & 19 \\
\hline
\end{tabular}

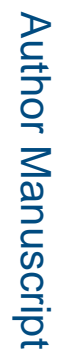


Table 2

Enzymatic parameters of the HIV-1 PR for processing of a peptide substrate.

\begin{tabular}{|c|c|c|c|}
\hline & $\mathbf{K}_{\mathrm{m}}(\boldsymbol{\mu M})$ & $\mathbf{V}_{\max }(\mathrm{RLU} / \min )$ & Relative $\mathbf{k}_{\text {cat }} / \mathbf{K}_{\mathrm{m}}$ \\
\hline Without RNA & 13.6 & 282,000 & $1 x$ \\
\hline With RNA & 3.6 & 784,000 & $10.5 x$ \\
\hline
\end{tabular}

